\title{
Characterization tests of GFRM coating as a strengthening technique for masonry buildings
}

\author{
Natalino Gattesco, Ingrid Boem* \\ Department of Engineering and Architecture, University of Trieste, Italy
}

\section{A R T I C L E I N F O}

\section{Article history:}

Received 28 November 2016

Revised 29 December 2016

Accepted 13 January 2017

Available online 16 January 2017

\section{Keywords:}

Masonry buildings

Seismic retrofitting

GFRP

Characterization tests

Bond tests

Tensile tests

\begin{abstract}
A B S T R A C T
Fiber Reinforced Mortars (FRM) represents a promising technique for the in-plane and out-of-plane reinforcement of existing masonry buildings, coupling effectiveness with compatibility needs. The paper focuses on a technique consisting in the application on the masonry surface of a $30 \mathrm{~mm}$ thick mortar coating with Glass Fiber-Reinforced Polymers (GFRP) meshes embedded, presenting and discussing the results of several characterization tests (pull-out, lap-splice, bond and tensile tests) performed so to investigate on the tensile properties and bond performances of the strengthening system, useful for correct design procedures and suitable also for numerical modeling.

The main aspects that has to be taken into account in the design of characterization tests are evidenced and the influence of some fundamental parameters (as the clamping system, the anchorage length, the boundary conditions and the sample dimensions) is discussed. Moreover, proper characterization tests permitted the estimation of the anchorage length to make effective the reinforcement and the definition of the stress-strain curve of the reinforced material subjected to tensile force.
\end{abstract}

(c) 2017 Elsevier Ltd. All rights reserved.

\section{Introduction}

The historical architectural substrate of many cities in the world is composed for the most of masonry constructions. Past and even recent seismic events extensively evidenced the high vulnerability of these buildings, due to the intrinsic low tensile strength of historic masonry and to design deficiencies against resistance to horizontal actions. The necessity to prevent in-plane and out-of-plane premature brittle failures of masonry elements with an effective reinforcement technique is frequently accompanied by the need to preserve the pre-existences, as often part of the cultural heritage.

The use of composite materials (based on fibers made of glass, carbon, aramidic, PBO...) in the structural retrofitting of masonry buildings started in the last decade of the XX century [1-3] and is gradually replacing traditional techniques employing steel elements and reinforced concrete, due to the competitive performances in terms of tensile resistance, lightweight, durability, fatigue behavior, no-corrosive and un-magnetic.

Depending on the element used (fabrics, strips, bars or meshes), the reinforcements are utilized in the mortar joint as reinforced repointing (Near Surface Mounted bars and strips - NSM), are

\footnotetext{
* Corresponding author.

E-mail address: boem@dicar.units.it (I. Boem).
}

glued directly to the masonry through either epoxy resin (Fiber Reinforced Polymers - FRP) or a thin mortar cement-based matrix (Fiber Reinforced Cementitious Matrix -FRCM) or are embedded in an inorganic mortar coating (Fiber Reinforced Mortars - FRM). Among the different available techniques [4-12], the use of Fiber Reinforced Mortars (FRM) or Textile Reinforced Mortars (TRM), is one of the most suitable for masonry elements. In fact, the use of inorganic matrix, instead of epoxy resins, to bond the reinforcement to the substrate ensures a better adhesion to an irregular surface such that of the masonry, provides fire resistance to the composite and protects it from UV rays and chemical agents. Moreover, the possible use of mortars made of natural binders, instead of cement, meets also the requirements of compatibility with historical masonry. Usually, the mortar layer thickness is of about $10 \mathrm{~mm}$ and the composites embedded in inorganic matrixes consist in unidirectional or bidirectional textiles or meshes (from $10 \times 10 \mathrm{~mm}^{2}$ up to $25 \times 25 \mathrm{~mm}^{2}$ grid dimension). These reinforcement methods have found application in the enhancement of masonry walls, columns, arches, vaults, bridges... However, despite the large number of experimental campaigns performed on the effectiveness of these techniques, limited investigations were conducted on the mechanical properties of these reinforcements in terms of tensile properties and bond performances on masonry substrate, useful to provide correct design procedures for an effective application and thus operation of the strengthening 
system. For this purpose, considering that the combination of variables associated with the use of FRMs is extremely high (e.g., matrix nature and thickness, textile material and percentage...), the RILEM Technical Committee 250-CSM “Composites for Sustainable Strengthening of Masonry" recently decided to deal with this specific topic, involving also, among the different activities, 15 laboratories for testing 8 GFRP (Glass Fiber-Reinforced Polymers) grid products coupled with different lime or cement matrices [13]. In fact, among the primary aims of the Committee, there is the identification and promotion of standardized experimental procedures for tensile and debonding tests on FRMs and the dissemination of proper application procedures for mortar-based composite materials on existing masonry structures.

The paper resumes the results of some characterization tests performed by the authors at the Laboratory of Building Materials and Structures of the University of Trieste, which was involved in the Round Robin Tests promoted by the Technical Committee 250-CSM. In particular, the analysed reinforcement technique consisted in GFRP preformed meshes (usually $66 \times 66 \mathrm{~mm}^{2}$ grid dimension) embedded in a $30 \mathrm{~mm}$ thick mortar layer. The durability behavior of the GFRP grids exposed to various environmental conditions was investigated by Corradi et al. [14]. The effectiveness of the technique in the seismic enhancement of masonry walls (inplane and out-of-plane) and vaults was investigated [15-18]; in these studies the importance of a good bond between the reinforcement and the masonry substrate and between the mesh and the mortar matrix emerged.

The presence of a mesh grid dimension and a mortar thickness outside of the usual standards for FRMs necessitated the execution of some preliminary tests (pull-out and lap-splice tests) on elemental samples, to check the interaction between the GFRP mesh and the mortar matrix. The results, which are resumed in the paper, had the intent to detect the main aspects which has to be taken into account in the proper design of the characterization tests for the considered reinforcement technique. Then, the shear and tensile characterization tests performed on GFRP reinforced mortar samples are described and discussed in detail. In particular, observations on the different failure mechanisms occurred in bond test at the varying of the bond length and of the mesh grid pitch and in tensile tests at the varying of the sample dimensions, gripping system and mesh grid pitch are made. Characterization tests permitted the assessment of the anchorage length to make effective the reinforcement and the definition of the stress-strain curve of the reinforced material (FRM), suitable also for numerical modeling.

\section{Technique description and material characteristics}

The GFRM technique (Fig. 1) consists in the application, on the masonry wall or vault surface, of a thin layer of scratch, the execution of some holes ( $25 \mathrm{~mm}$ diameter), the application of the GFRP mesh, the insertion of L-shaped GFRP connectors into the holes, injected with thixotropic cementitious mortar. To improve the anchorage of the connector in the mortar layer, an additional GFRP mesh device is used. Finally, a mortar coating, about $30 \mathrm{~mm}$ thick is applied.

The wires of the GFRP meshes are composed of Alkali-Resistant glass fibers embedded in a thermosetting resin made of epoxy vinylester with benzoyl peroxide as catalyst. The mesh is formed by twisting the fibers of the wires in one direction across the wires in the perpendicular direction, which fibers, differently, remain parallels (Fig. 2). The GFRP meshes used in practice for such a reinforcement technique have grid dimensions of $33 \times 33 \mathrm{~mm}^{2}$, $66 \times 66 \mathrm{~mm}^{2}$ and $99 \times 99 \mathrm{~mm}^{2}$; the dry fiber cross section in a wire is $3.8 \mathrm{~mm}^{2}$.
Preformed GFRP meshes are produced in rolls, with twisted fibers wires in the warp direction and parallel fibers wires in the weft one. Thus, for simplicity and speed of installation, the twisted fibers wires are commonly oriented in the vertical direction of a masonry wall and in the transversal direction of a masonry vault.

The main geometrical and mechanical characteristics of the GFRP wires are summarized in Table 1.

The global equivalent cross section of the wires was detected, according to the procedure presented in CNR DT 203/2006, Appendix B [19]. The tests consisted in immersing some portions of the wires (minimum total length of $200 \mathrm{~mm}$ ) in a graduated cylinder filled with water and measuring the volume increase of the liquid.

Tensile tests were performed according to CNR DT 203/2006, Appendix B [19]. The test samples were constituted by single wires having a length of about $500 \mathrm{~mm}$ extracted from the mesh by cutting in half the transversal wires. The clamping heads were created by inserting both the ends of the wire in an aluminum cylinder (diameter $19 \mathrm{~mm}$, thickness $1.5 \mathrm{~mm}$, length $100 \mathrm{~mm}$ ) injected with a high-performances bi-component epoxy anchoring. A universal testing machine "Galileo" was used (Fig. 3.); the load was measured using a pressure transducer (capacity $20 \mathrm{kN}$ ), connected with a digital acquisition system interfaced with a laptop. To survey the axial elongation during test, a linear potentiometer transducer was applied $(10 \mathrm{~mm}$, error lin. $\pm 0.10 \%$, base length of $63 \mathrm{~mm}$ ).

The twisted fibers wires showed a tensile resistance lower than that of parallel fibers wires. This is probably due to the different tension occurring in each fiber during the tensile test, because of the twisting, so that not all fibers reach the ultimate resistance at the same time. During the tensile tests of twisted fibers wires, a gradual untwisting was noted at the increasing of the load.

In the considered reinforcement technique, different types of mortar may be utilized for the coating made with calcareous or siliceous sand and using natural binders, cement and pozzolanic additives [20]. As an example, a lime and cement mortar $(300 \mathrm{~kg}$ of hydraulic lime and $100 \mathrm{~kg}$ of Portland cement per $\mathrm{m}^{3}$ of mortar) with siliceous sand was here considered for characterization tests. Experimental tests on prismatic $\left(40 \times 40 \mathrm{~mm}^{2}\right.$ cross section, $160 \mathrm{~mm}$ length) and cylindrical $(100 \mathrm{~mm}$ diameter, $200 \mathrm{~mm}$ height) samples evidenced for such a mortar an average compressive strength $f_{c, c}=6.3 \mathrm{MPa}$ (COV 11\%) [21], a flexural tensile strength $f_{f, c}=1.6 \mathrm{MPa}$ (COV 3\%) [21], a tensile strength $f_{t, c}=1.1 \mathrm{MPa}(\mathrm{COV} 8 \%)$ [22] and an average Young modulus $E_{c}=14430 \mathrm{MPa}(\operatorname{COV} 14 \%)[23]$.

\section{Pull-out and lap-splice tests}

Some preliminary tests were carried out on very simple, small size mortar specimens with GFRP mesh embedded, so to detect the main aspects which may influence the interaction between the composite and the inorganic matrix and determine the most suitable test setup for the characterization of this reinforcement technique. For such a purpose, pull-out and lap-splice tests were performed. It is observed that test focuses on twisted fibers wires oriented in the load direction, accounting for the typical mesh positioning in masonry walls subjected to out-of-plane vertical bending and masonry vaults subjected to horizontal transversal loads (see Section 2). However, some comparisons with the parallel fibers wires bonding performances are made.

\subsection{Pull-out tests}

The pull-out test samples consist in $30 \times 180 \times 180 \mathrm{~mm}^{3}$ mortar plates with $66 \times 66 \mathrm{~mm}^{2}$ GFRP mesh embedded centered in the mortar thickness. Two transversal, parallel fibers, wires and three longitudinal, twisted fibers, wires were considered; the 

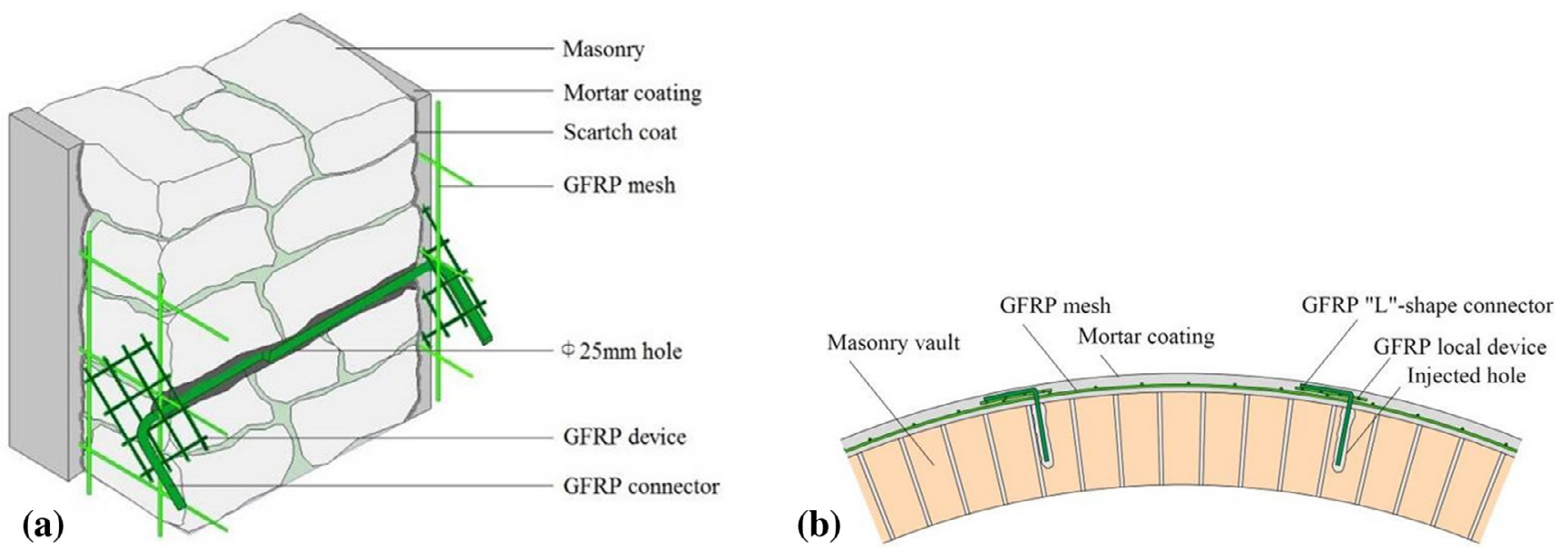

Fig. 1. Detailing of the GFRP reinforced mortar coating system applied (a) on both sides of a masonry wall or (b) at a vault extrados.

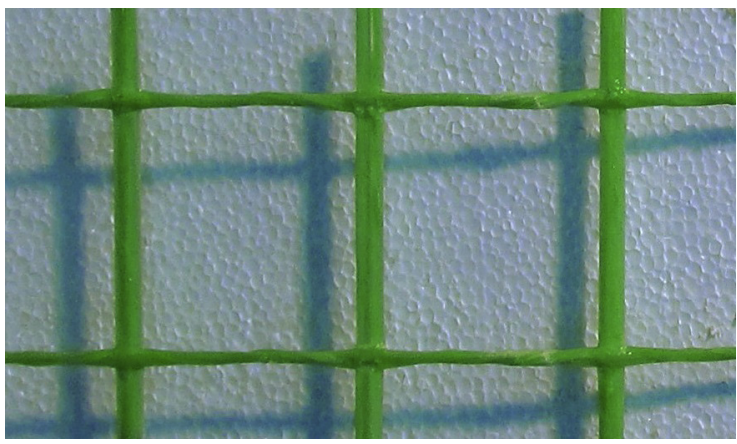

Fig. 2. Detail of a GFRP mesh: the warp (twisted fibers wires) is horizontal and the weft (parallel fibers wires) is vertical.

central longitudinal wire was extended outside the mortar, for about $260 \mathrm{~mm}$, so to permit the application of the tensile force.

The preparation procedure consisted in the positioning of a first frame of wooden slats (cross section $15 \times 15 \mathrm{~mm}^{2}$ ) on a plywood base covered with plastic film; specific grooves in the slats facilitated the positioning of the GFRP mesh on the frame. A second frame of wooden slats (section $15 \times 15 \mathrm{~mm}^{2}$ ) was screwed on the one below, blocking the mesh. Then, the mortar was casted inside the wooden formwork, taking care to vibrate the cast so to compact adequately the mould. During the casting phase, two rubber tubes (30 mm length) were used as spacers, in correspondence of the central wire, so to avoid the local damage of the mortar in correspondence of the mortar layer edges. The actual bond length between the central GFRP wire and the mortar was, thus, equal to $120 \mathrm{~mm}$. The extrados surface of the casted mortar was leveled by float and covering with cotton fabric maintained wet, so to avoid the accelerated evaporation of water in the mixture. The formwork was removed after three days of curing. The specimens were maintained in a temperature controlled room $\left(23^{\circ} \mathrm{C} \pm 2^{\circ} \mathrm{C}\right)$ until the achievement of maturation (about 30 days from the cast). Then, at the free end of the central longitudinal wire, the clamping head of the sample was created by means of aluminum cylinder injected with anchoring resin (see tensile tests on GFRP wires in Section 2).

The same testing machine and measurement equipment employed in tensile tests on GFRP wires (Section 2) was used. A contrast frame, composed by two horizontal UPN 80 metallic elements jointed with two vertical M14 steel bars, was connected to the lower clamp of the machine. For the installation of the specimen, the free end of the central wire was inserted in a central hole created in the upper UPN element of the contrast frame and the aluminum cylinder was fixed to the upper clamp of the machine. The potentiometer transducer was pinned to the central GFRP wire and was used to monitor the relative displacement between the mesh and the upper UPN element. The base length was $105 \mathrm{~mm}$ thus, at the beginning of the test, the transducer was able to survey the elongation of a $140 \mathrm{~mm}$ portion of the wire. The tests setup and the main specimen characteristics are illustrated in Fig. 4. The tests were performed after about 70 days air curing; the testing rate was $0.05 \mathrm{kN} / \mathrm{s}$

Six specimens were tested: the samples were signed through an identifier which indicates the type of tests (PO for pull-out tests), the geometry of the mortar coating (P for plate), the fibers orientation of the central wire ( $T$ for twisted fibers) and distinguishes through numbers (1-6) specimens with identical characteristics. The maximum pull-out force $T_{\max }$, the wire-mortar slip $\Delta\left(T_{\max }\right)$ corresponding to maximum load and the failure mode are reported in Table 2; the curves representing the load in function of the global displacement monitored by the transducer are plotted in Fig. 5 . The load-displacement curve of a GFRP twisted fibers wire, referred to a base length of $140 \mathrm{~mm}$ is also reported, so to evaluate the contribution to the global displacement due to the wire deformation in the initial base length and detect the beginning of the wire slip.

Table 1

Tensile characterization test on a GFRP wire: dry fiber cross section $A_{\text {fib }}$, global cross section $A_{\text {tot }}$, tensile resistance $T_{w}$ and axial stiffness $E A_{t o t}$.

\begin{tabular}{|c|c|c|c|c|c|c|}
\hline Mesh wire & $A_{f i b}\left[\mathrm{~mm}^{2}\right]$ & $A_{\text {tot }}\left[\mathrm{mm}^{2}\right]$ & $T_{w}[\mathrm{kN}]$ & COV [\%] & $E A_{\text {tot }}[\mathrm{kN}]$ & $\operatorname{COV}[\%]$ \\
\hline $33 \times 33 \mathrm{~mm}^{2}-$ twisted fibers wire & 3.8 & 7.29 & 3.97 & 9 & 219 & 9 \\
\hline $33 \times 33 \mathrm{~mm}^{2}-$ parallel fibers wire & 3.8 & 9.41 & 4.88 & 12 & 285 & 12 \\
\hline $66 \times 66 \mathrm{~mm}^{2}-$ twisted fibers wire & 3.8 & 7.29 & 4.22 & 14 & 219 & 14 \\
\hline $66 \times 66 \mathrm{~mm}^{2}-$ parallel fibers wire & 3.8 & 9.41 & 4.71 & 8 & 264 & 1 \\
\hline $99 \times 99 \mathrm{~mm}^{2}-$ twisted fibers wire & 3.8 & 7.29 & 4.01 & 18 & 207 & 15 \\
\hline $99 \times 99 \mathrm{~mm}^{2}-$ parallel fibers wire & 3.8 & 9.41 & 4.65 & 15 & 245 & 4 \\
\hline
\end{tabular}




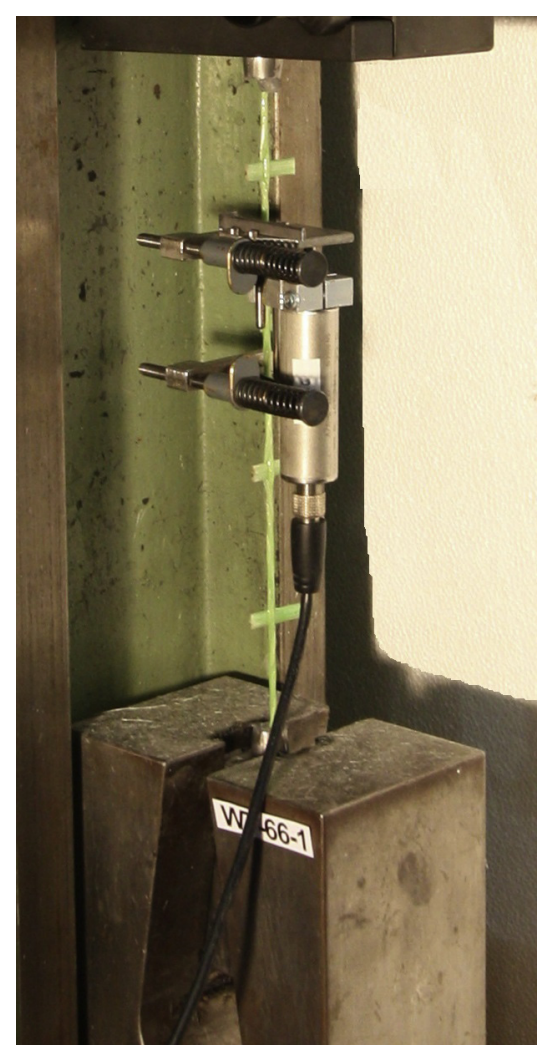

Fig. 3. Tensile characterization test on a GFRP wire.

In general, the specimens manifested an initial linear behavior, which is in good agreement with the GFRP wire stiffness until a load of $2.2 \mathrm{kN}$; then, a gradual decreasing of stiffness emerged, due to the slip of the central wire with respect to mortar (starting loss of chemical adherence at wire-mortar interface). Specimens attain to similar peak values $(4.14 \mathrm{kN}$, standard deviation $10 \%$ of the mean value). In specimens PO-PT1, PO-PT3 and PO-PT5 the wire rupture occurred (Fig. 6.a) after reaching the maximum resistance; then the load rapidly dropped down. Differently in specimen PO-PT2, PO-PT4 and PO-PT6 the gradual formation of a vertical crack, in correspondence of the central wire, occurred (Fig. 6.b); however the load continue to increase; the collapse was achieved in consequence of the mesh central nodes rupture, which determined a gradual load decrease. At the end of the test it was possible to inspect the failure mode of the mesh nodes: it emerged the cutting through of the transversal wires (Fig. 6.c). It is evidenced that the cracking formation was probably induced by the geometry of the specimen: in fact, the slightly bending deformation of the upper steel element of the contrast frame and possible minor irregularity in the mortar plate edge in contact with the frame caused a concentration of the reactions at the lateral ends of the mortar layer, producing a parasitic bending moment which caused the splitting of the matrix. Thus, for comparison, pull-out test were performed on samples of different geometry, avoiding the splitting.

In particular, mortar cylinders $(100 \mathrm{~mm}$ in diameter and $200 \mathrm{~mm}$ in height) with a single longitudinal twisted fibers wire, of a $66 \times 66 \mathrm{~mm}^{2}$ GFRP mesh were tested. The wire was centered in the cylinder cross section and two transversal wires embedded in the mortar and cut in half at both ends were considered. The mortar was casted in PVC cylindrical formworks and $40 \mathrm{~mm}$ length rubble tubes were used as spacers (actual bond length equal to $120 \mathrm{~mm}$, as in plate samples).

The same test setup used for plate samples was adopted. A $5 \times 120 \times 120 \mathrm{~mm}^{3}$ steel plate, with a central hole, was interposed between the upper UPN80 of the contrast frame and the cylinder, so to uniformly distribute the reactions of the contrast frame to the upper base of the mortar sample. At the beginning of the test, the displacement transducer was able to monitor the elongation of a $140 \mathrm{~mm}$ portion of the GFRP wire. Six specimens were tested; the main results are reported in Table 2 and the curves representing the load in function of the global slip monitored by the transducer are plotted in Fig. 5.a. In the sample identifier, the letter " $\mathrm{C}$ " refers to the cylindrical shape of the mortar. An average maximum load (a)

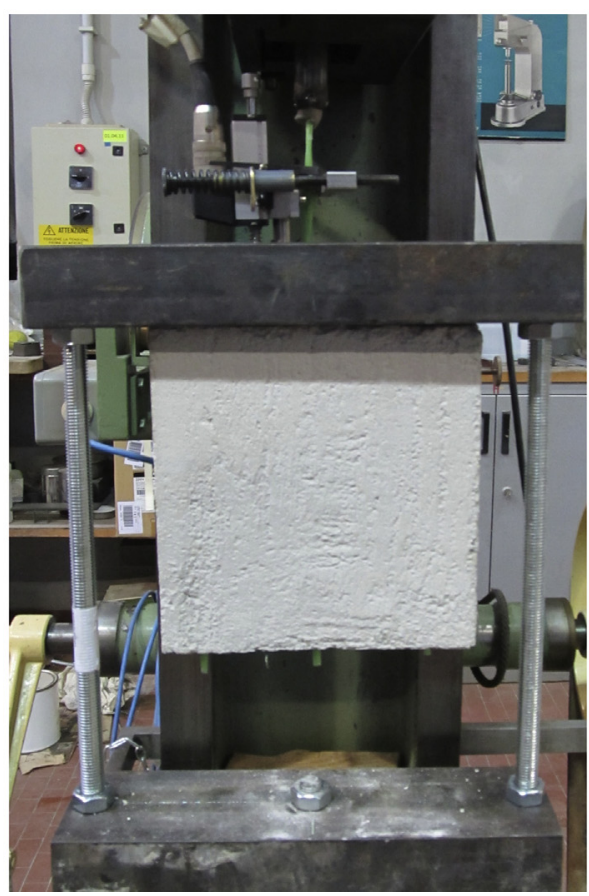

(b)

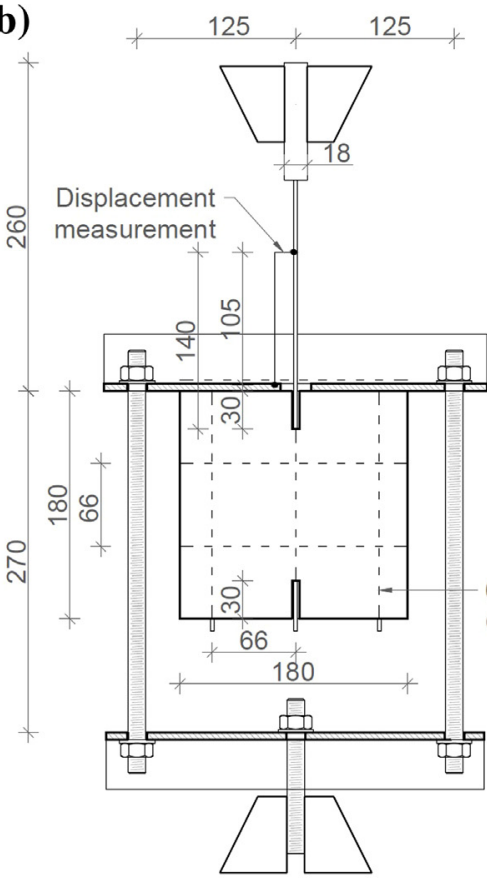

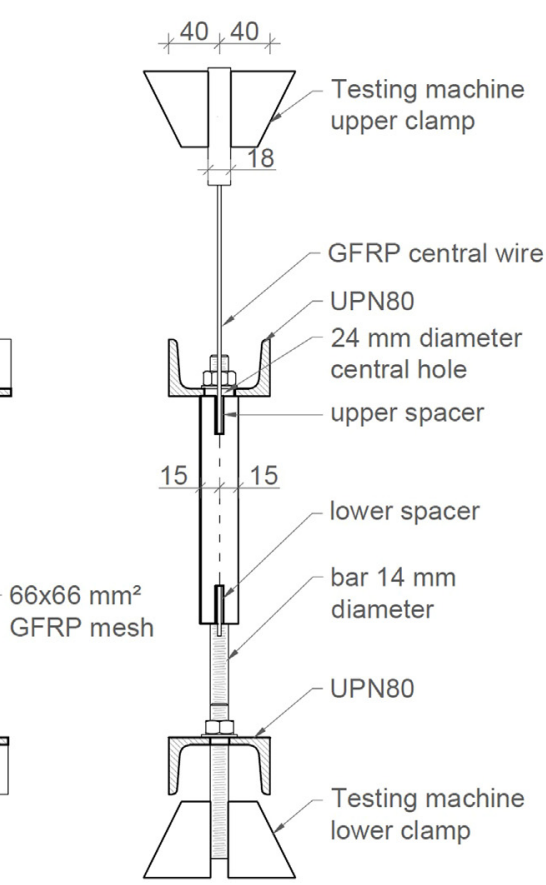

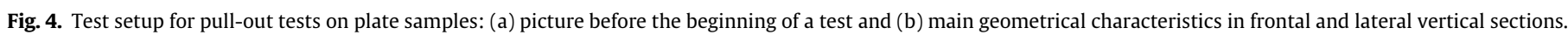


Table 2

Pull-out tests on GFRP reinforced mortar layers.

\begin{tabular}{llll}
\hline ID & $\begin{array}{l}T_{\max } \\
{[\mathrm{kN}]}\end{array}$ & $\begin{array}{l}\Delta\left(T_{\max }\right) \\
{[\mathrm{mm}]}\end{array}$ & Failure mode \\
\hline PO-PT1 & 3.81 & 3.22 & Central wire rupture \\
PO-PT2 & 3.71 & 3.35 & Mortar splitting and mesh nodes failure \\
PO-PT3 & 4.88 & 5.57 & Central wire rupture \\
PO-PT4 & 4.21 & 4.63 & Mortar splitting and mesh nodes failure \\
PO-PT5 & 3.94 & 3.84 & Central wire rupture \\
PO-PT6 & 4.30 & 4.16 & Mortar splitting and mesh nodes failure \\
PO-CT1 & 4.98 & 4.58 & Wire rupture \\
PO-CT2 & 4.02 & 2.48 & Wire rupture \\
PO-CT3 & 3.69 & 3.40 & Wire rupture \\
PO-CT4 & 4.70 & 4.35 & Wire rupture \\
PO-CT5 & 4.39 & 3.61 & Wire rupture \\
PO-CT6 & 4.41 & 3.82 & Wire rupture \\
PO-PP1 & 3.96 & 3.32 & Mortar splitting and central wire extraction \\
PO-PP2 & 5.05 & 4.00 & Mortar splitting and central wire extraction \\
PO-PP3 & 3.92 & 2.61 & Mortar splitting and central wire extraction \\
PO-PP4 & 3.42 & 2.82 & Mortar splitting and central wire extraction \\
PO-PP5 & 4.46 & 2.97 & Mortar splitting and central wire extraction \\
PO-PP6 & 3.71 & 2.83 & Mortar splitting and central wire extraction \\
\hline
\end{tabular}

of about $4.41 \mathrm{kN}$ was attained (standard deviation 12\%) and the wire rupture always occurred (Fig. 6.d); then the load rapidly dropped down. No significant differences emerged in the loaddisplacement curves in respect to those concerning plate samples collapsed for the wire rupture.

The comparison of the results of plate and cylindrical samples evidenced that the splitting failure mode is related to the particular test setup used for plate samples. Actually, the stress state of the GFRP reinforced mortar coating applied on masonry does not affect a single mesh wire, involving a wider area of reinforcement. Thus, it is important to perform characterization tests reproducing as close as possible the actual stress state of the mesh and reinforcement boundary conditions.

However, some important findings emerged. At first, the results showed that, from a tensile load of about $2.2 \mathrm{kN}$, a gradual detachment of the GFRP wire from the mortar occurs. Nevertheless, a wire-mortar bond length of at least $120 \mathrm{~mm}$ may ensure the exploitation of the whole mesh resistance, avoiding the premature reinforcement collapse for composite slippage. Actually, the tests permitted to evidence that the mesh nodes are able to provide an effective contribution against the wire slippage: the resistance of two mesh nodes (deduced from the tests PO-PT2, PO-PT4 and PO-PT6, where the chemical adhesion between the central wire and the mortar was completely nullified by the occurrence of splitting) resulted quite close to the tensile resistance of the wire.

Six additional plate samples were tested so to check the performances of the reinforcement when the parallel fibers wire is loaded in tension (PO-PP tests in Table 2). The tests (Fig. 5.b) evidenced the beginning of the loss of chemical adherence at wiremortar interface of the central parallel fibers wire in correspondence of a load of about $1.8 \mathrm{kN}$; this value resulted lower that that emerged from PO-PT tests, where the wire roughness is realistically higher, due to twisting. At the increasing of the load, also the gradual vertical mortar splitting occurred; the local bend of the wire in correspondence of the intersection with the transversal (a)

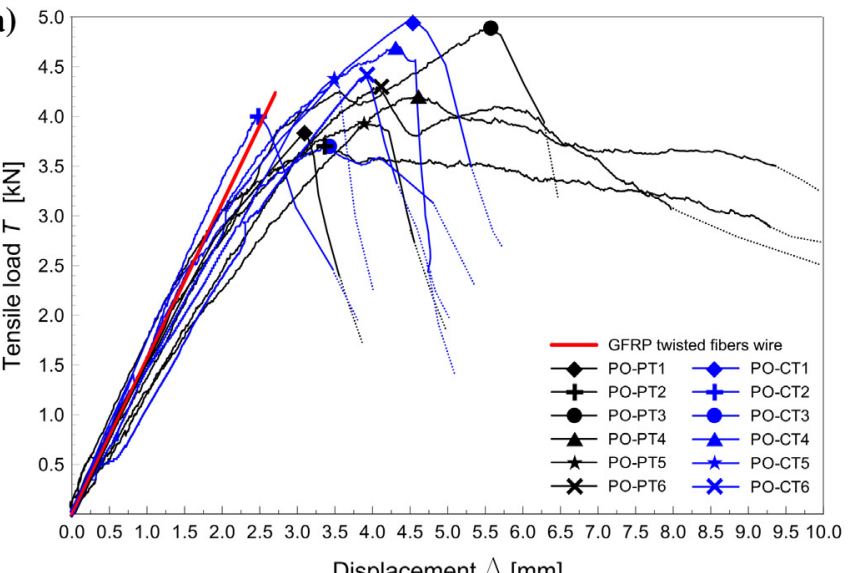

(b)

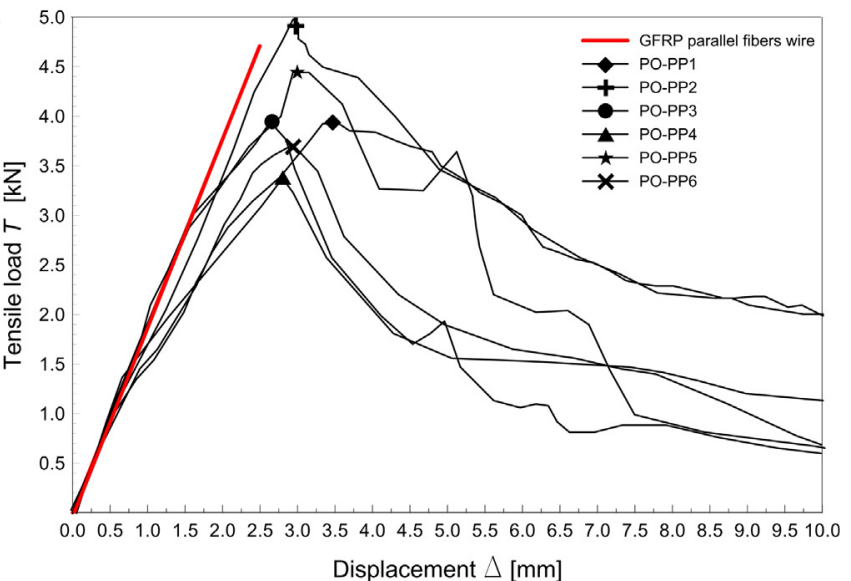

Fig. 5. Load vs. displacement curves of the pull-out tests: (a) specimens PO-PT and PO-CT and (b) specimens PO-PP.

(a)

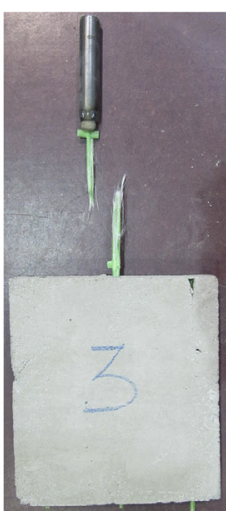

(b)

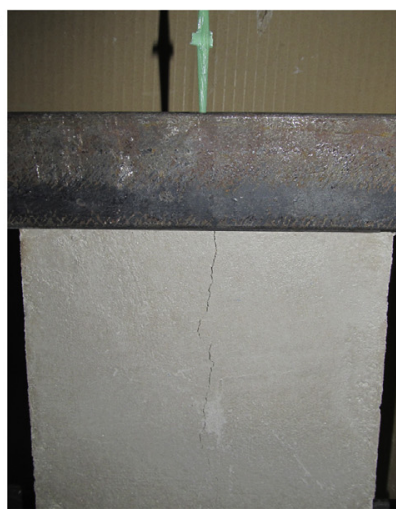

(c)

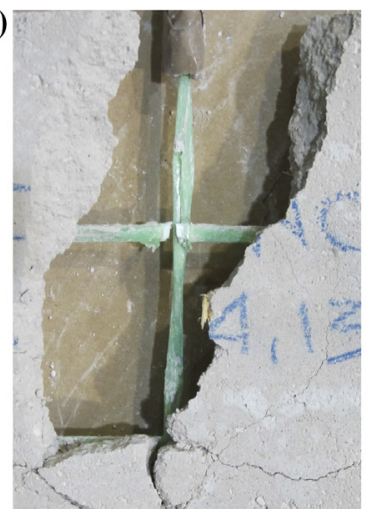

(d)

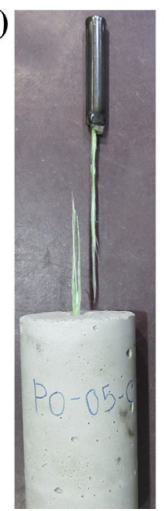

(e)

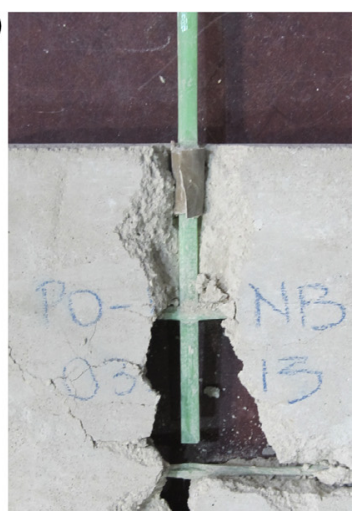

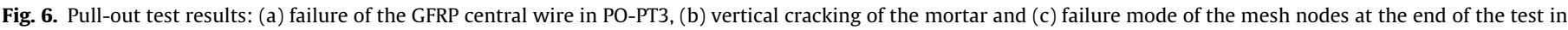
PO-PT4, (d) failure of the GFRP wire in PO-CT5, (e) slippage of the central wire from the transversal ones at the end of the test PO-PP2. 
(a)

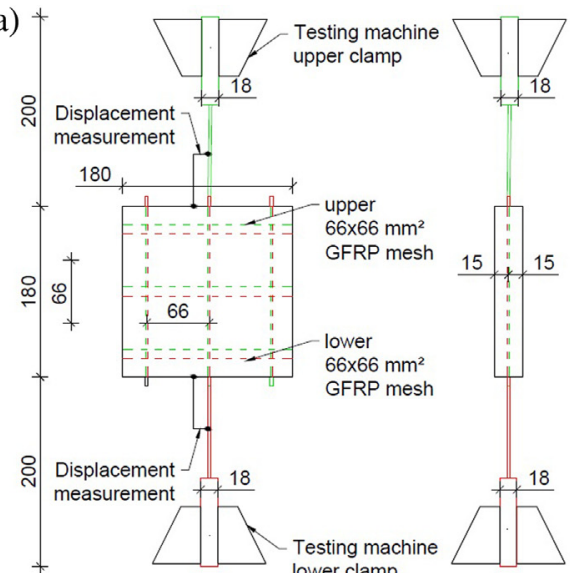

(b)

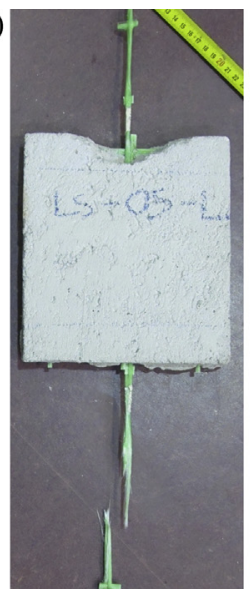

(c)

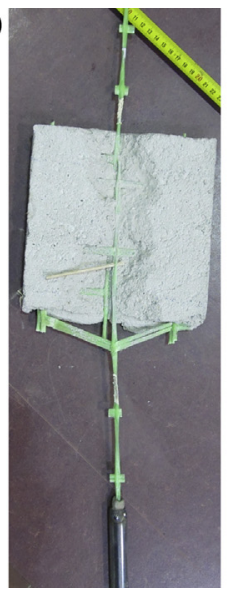

(d)

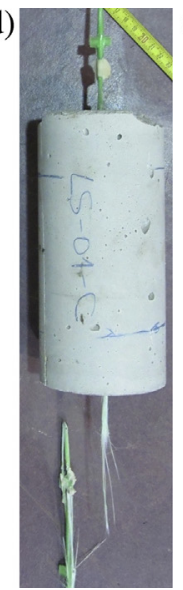

(e)

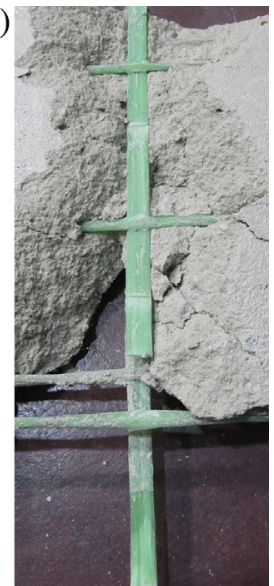

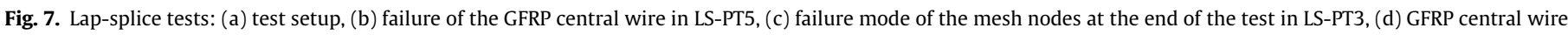
rupture in LS-CT1 and (e) central wire slip from the transversal ones at the end of test LS-PP2.

wires (twisted) caused an increase of the bond resistance. The collapse was achieved with the extraction of the central wire from transversal ones (Fig. 6.e) in correspondence of an average maximum load of about $4.09 \mathrm{kN}$ (standard deviation 14\%). This load is lower than the tensile resistance of a parallel fibers wire (see Table 1 ) but it is quite close to the peak load attained in PO-PT samples.

\subsection{Lap-splice tests}

Lap-splice samples (Fig. 7.a) consisted in $30 \times 180 \times 180 \mathrm{~mm}^{3}$ mortar plates with embedded two GFRP mesh having the same characteristics of pull-out plate samples. The meshes were overlapped and centered in the mortar thickness and an offset of about 10-12 $\mathrm{mm}$ was created between the transversal wires. The actual bond length was $180 \mathrm{~mm}$. The longitudinal central wires were centered in the plate width and extended outside the mortar at opposite sides for about $200 \mathrm{~mm}$, so to permit the application of the tensile force by clamping the injected aluminum cylinders installed at the wire ends to the universal testing machine "Galileo". Linear potentiometer transducers monitored the displacement between the wires and the mortar (base length $50 \mathrm{~mm}$ ).

The tests setup and the main specimens characteristics are illustrated in Fig. 7.a. Six specimens were tested: the samples were signed through an identifier which indicates the type of tests (LS for lap-splice tests) the geometry of the mortar coating ( $\mathrm{P}$ for plate), the fibers orientation in longitudinal wires ( $T$ for twisted fibers wires) and distinguishes through sequential numbers the specimens with identical characteristics. The maximum force $T_{\max }$, the wire-mortar slip $\Delta\left(T_{\max }\right)$ corresponding to maximum load and the failure mode are reported in Table 3.

The load-displacement behavior (Fig. 8.a) shows a linear first branch up to a tensile load of $2.0-2.2 \mathrm{kN}$; then a stiffness reduction occurred, due to slip of the central wire with respect to mortar (starting loss of chemical adherence at wire-mortar interface). The collapse occurred at an average load of $4.49 \mathrm{kN}$ (standard deviation $7 \%$ of the mean value), generally in consequence of the tensile rupture of a central wire, outside of the mortar (Fig. 7.b). Exception for LS-PT3, where a horizontal cracking of the mortar occurred in correspondence of a transversal wire, then the progressive central nodes failure occurred (Fig. 7.c). In LS-PT5, a local damage of the mortar at the graft of the central wire emerged, however this did not change appreciably the sample behavior.

Six cylindrical samples (LS-CT in Table 3) with the same overlapping length were tested for comparisons: the wire
Table 3

Lap-splice tests on GFRP reinforced mortar layers: $T_{\max }$ maximum force, $\Delta\left(T_{\max }\right)$ wire-mortar slip in correspondence of $T_{\max }$ and failure mode.

\begin{tabular}{llll}
\hline ID & $\begin{array}{l}T_{\max } \\
{[\mathrm{kN}]}\end{array}$ & $\begin{array}{l}\Delta\left(T_{\max }\right) \\
{[\mathrm{mm}]}\end{array}$ & Failure mode \\
\hline LS-PT1 & 4.97 & 2.04 & Central wire rupture \\
LS-PT2 & 4.62 & 1.73 & Central wire rupture \\
LS-PT3 & 4.10 & 1.54 & Mortar splitting and mesh nodes failure \\
LS-PT4 & 4.40 & 2.25 & Central wire rupture \\
LS-PT5 & 4.19 & 1.56 & Central wire rupture \\
LS-PT6 & 4.65 & 1.97 & Central wire rupture \\
LS-CT1 & 4.36 & 1.79 & Wire rupture \\
LS-CT2 & 4.94 & 1.77 & Wire rupture \\
LS-CT3 & - & - & Premature wire failure at clamping \\
LS-CT4 & 4.78 & 2.23 & Wire rupture \\
LS-CT5 & 4.91 & 1.73 & Wire rupture \\
LS-CT6 & 4.47 & 1.71 & Wire rupture \\
LS-PP1 & 4.05 & 1.93 & Central wire extraction \\
LS-PP2 & 3.63 & 1.65 & Central wire extraction \\
LS-PP3 & 3.72 & 2.19 & Central wire extraction \\
LS-PP4 & 3.63 & 1.65 & Central wire extraction \\
LS-PP5 & - & - & Premature wire failure at clamping \\
LS-PP6 & - & - & Premature wire failure at clamping \\
\hline
\end{tabular}

rupture (Fig. 7.d) was always attained (average load $4.69 \mathrm{kN}$, standard deviation 6\%) and the load-displacement curves resulted comparable to those obtained in LS-PT specimens (Fig. 8.a).

Finally, six additional tests on plate samples with GFRP parallel fibers wires loaded in tension were performed (LS-PP in Table 3). The tests evidenced the starting of loss of adherence at wiremortar interface at a load of about $1.8 \mathrm{kN}$ (Fig. 8.b), but due to the local bend of the wire in correspondence of the intersection with the transversal wires (twisted) further bond resistance was obtained. The collapse, in fact, was achieved for an average load of $3.76 \mathrm{kN}$ (standard deviation 5\%), with the extraction of the lower central wire from transversal ones (Fig. 7.e).

The results of lap-splice tests evidenced that an overlapping of $180 \mathrm{~mm}$ permits the exploitation of the whole GFRP mesh resistance, when the tensile direction is that of twisted fibers wires; on the contrary, the premature wire reinforcement slippage occurred when loading in tension the parallel fibers wires, but for values of the load almost equal to those obtained in tests with twisted wires. The comparison of the results of plate and cylindrical samples evidenced that both tests are suitable to reproduce with good accuracy the actual boundary conditions. 


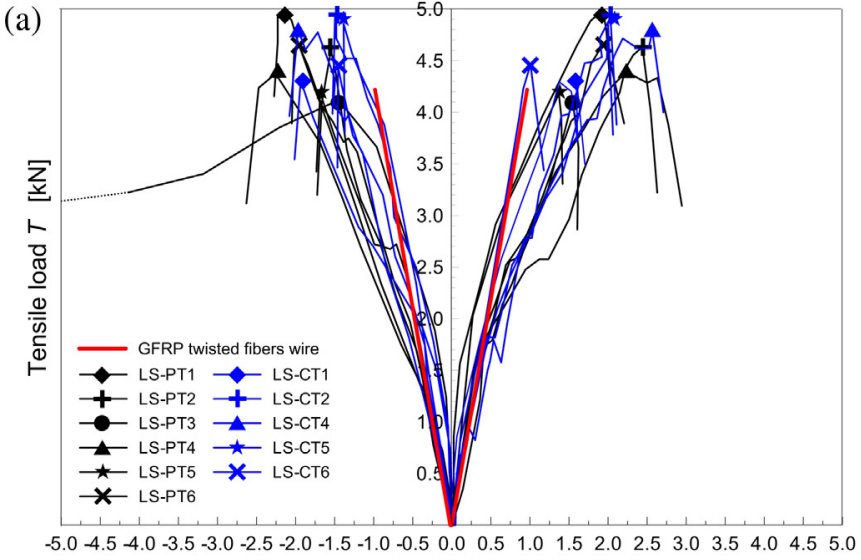

Lower wire displacement $\Delta_{L}[\mathrm{~mm}] \quad$ Upper wire displacement $\Delta_{U}[\mathrm{~mm}]$

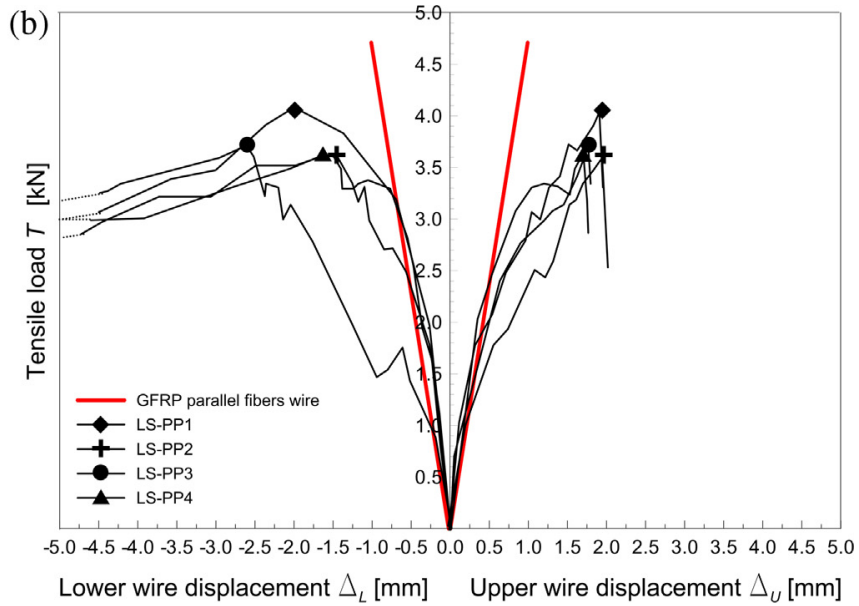

Fig. 8. Load vs. displacement curves of the lap-splice tests: (a) specimens LS-PT and LS-CT and (b) specimens LS-PP.

\section{Bond tests}

Some bond tests were performed so to evaluate the shear performances of the GFRP reinforced mortar coating technique applied on a masonry substrate. The test setup and the results are described in the following.

\subsection{Specimens characteristics}

Specimens were composed by solid brick masonry wallets $\left(250 \times 315 \times 120 \mathrm{~mm}^{3}\right)$ to which a $30 \mathrm{~mm}$ thick GFRP reinforced mortar coating was applied on one face, leaving a distance from the wallet base of about $30 \mathrm{~mm}$. The GFRP mesh, which exceeded from the mortar coating layer in correspondence of the bottom side of the coating, was placed in the center of the mortar layer thickness and the twisted wires were disposed in the longitudinal direction.

A $66 \times 66 \mathrm{~mm}^{2}$ GFRP mesh was applied for the reinforcement, assuming different lengths for the mortar coating $(120 \mathrm{~mm}$, $180 \mathrm{~mm}$ and $240 \mathrm{~mm}$ ) and keeping a constant width of $132 \mathrm{~mm}$. The three dimensions were chosen, based on the findings of preliminary pull-out tests (Section 3), so to check the influence of the bond length on the resistance and collapse mode of the reinforcement, which may occur for mesh wire failure, mesh wire slippage from mortar matrix or mortar slippage from the masonry substrate. Moreover, for the latter case, the presence of a $33 \times 33 \mathrm{~mm}^{2}$ GFRP mesh, instead of a $66 \times 66 \mathrm{~mm}^{2}$ one, was also considered. Five sample were tested for each of the four described layouts (Fig. 9).

The packaging of the samples consisted in the preparation and curing of the masonry wallets, which were then arranged so to dispose face-up the surface to be reinforced. Then, the procedure followed the same steps described in subsection 3.1 for pull-out samples, taking care in wetting the masonry surface before casting, so to avoid the absorption of the water of the mortar. The tests were performed after about 78-93 days of mortar coating curing.

The average compressive strength of the solid bricks was determined in accordance with EN 772-1:2011 + A1:2015 [24]. Each sample was composed of a single solid unit. The results of the six tests performed provided an average compressive strength of $20.8 \mathrm{MPa}$ (COV 4\%). The normalized compressive strength resulted equal to $15.7 \mathrm{MPa}$. The masonry mortar was made of premixed mortar based on lime and cement. The mechanical properties were determined through flexural and compressive strength tests [21] carried out on nine $40 \times 40 \times 160 \mathrm{~mm}^{3}$ prismatic specimens. It was obtained an average flexural strength of $2.1 \mathrm{MPa}$ (COV 13\%) and an average compressive strength of $5.4 \mathrm{MPa}$ (COV 4\%).

To facilitate the execution of the experimental bond tests, a holding head in correspondence of the free end of the GFRP mesh was created once the curing was completed. In particular, two GFRP pultruded plates (dimensions $8 \times 130 \times 130 \mathrm{~mm}^{3}$ ), were coupled with the interposition of the GFRP mesh and the injection of a bicomponent epoxy resin.
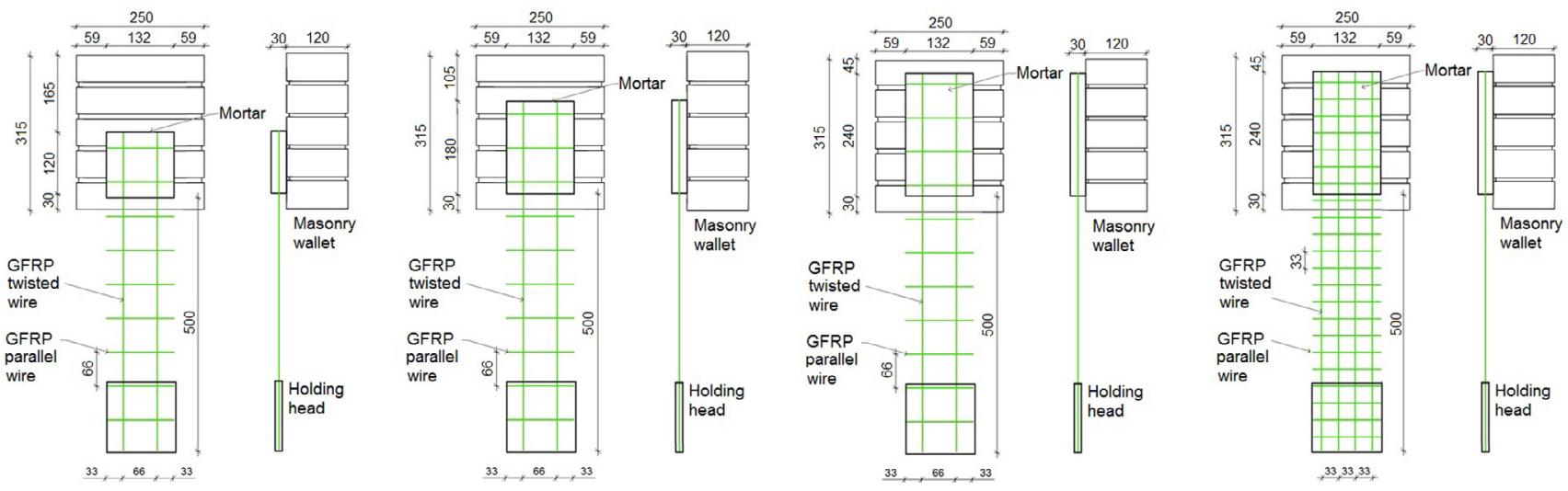

Fig. 9. Characteristics of the samples for bond tests: (a) type A66-1, (b) A66-2, (c) A66-3 and (d) type A33-1. 
(a)

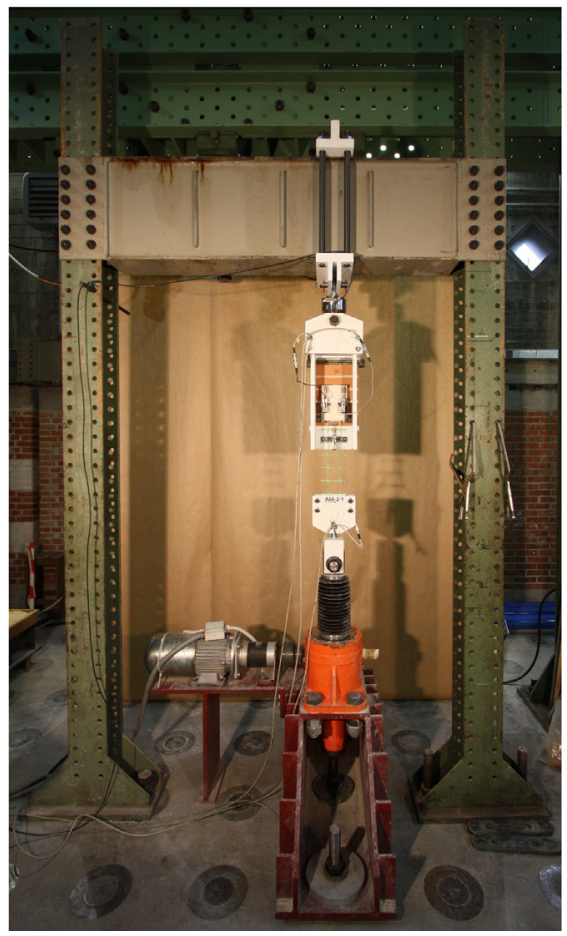

(b)

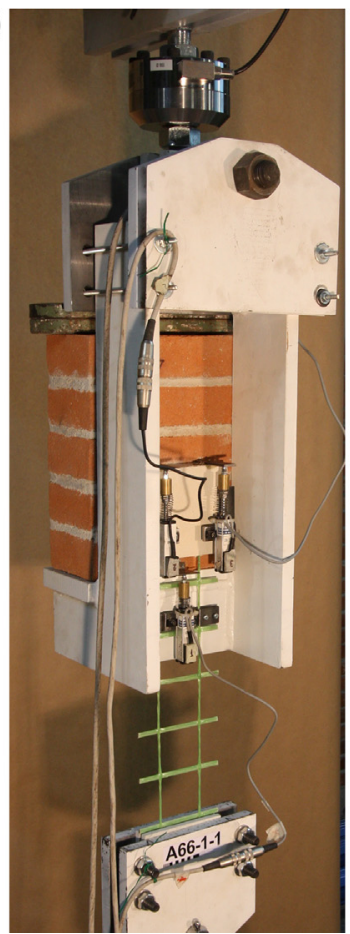

(c)

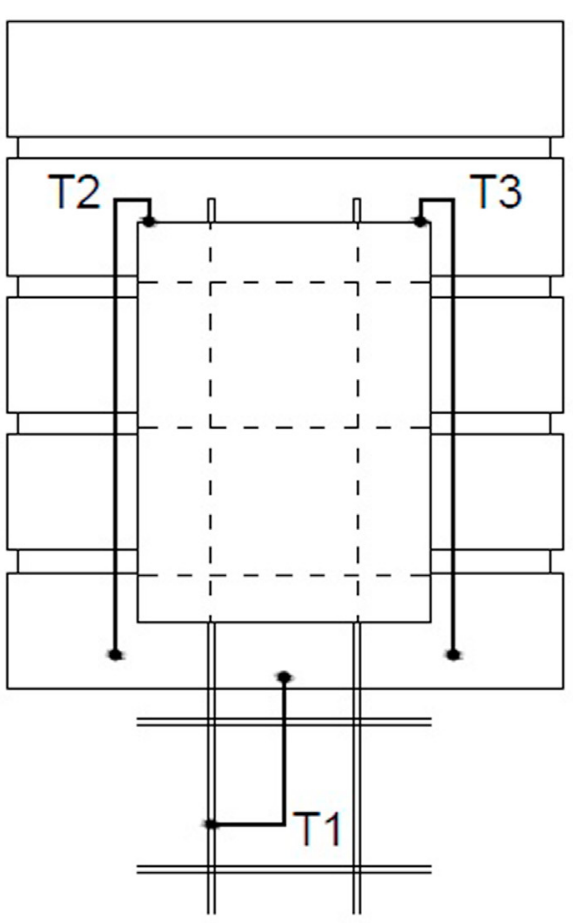

Fig. 10. Bond test apparatus: (a) global view, (b) detail and (c) displacements measurements.

\subsection{Test setup and loading procedure}

The apparatus (Fig. 10.a-b) consisted of a metallic portal composed by two posts and a beam, jointed by bolts. The portal was connected to the reinforced concrete foundation of the test laboratory by couples of anchor bolts. A metallic basement, fixed through anchor bolts to the foundation, was placed between the two posts and an electro-mechanical actuator (300 kN capacity, $300 \mathrm{~mm}$ stroke), was installed at the top of this element. On the top of the actuator, two coupled steel plates were installed so to create the clamping system for the pultruded plates head of the samples. The holding was realized by friction, tightening couples of bolts M14 placed at the lateral ends of the steel plates). At the intrados and extrados of the beam of the metallic portal, two welded plates were positioned and coupled by means of steel bars. A loading cell $(50 \mathrm{kN})$ was hanged to the lower plate, by means of a knuckle joint.

Below the cell, a metallic device, shaped as a seat, was connected so to support the masonry wallet. The device was set so to maintain the GFRP mesh in the vertical direction and it was properly designed so to be guarantee a sufficient stiffness and ensure the vertical alignment of the load along the specimens, taking care to avoid secondary forces, perpendicular to the masonry surface, which could anticipate the sample failure. The interposition of knuckle joints both between the actuator and the coupled plates holding system and between the loading cell and the steel device supporting the specimen permitted to overcome for possible parasitic bending forces that may arise in the samples, due to possible small geometric irregularities. The metallic pins used to join the different elements of the apparatus were calibrated to avoid tolerances. The test apparatus was dimensioned so to limit as close as possible the elastic deformation of the metallic elements and connections: the deformation of the apparatus associated to a tensile force on the specimen equal to $10 \mathrm{kN}$ was estimated approximately equal to $0.04 \mathrm{~mm}$.

Three potentiometer transducers were applied on the specimens, as illustrated in Fig. 10.c. In particular, potentiometer T1 measured the displacement between the GFRP mesh and the base of the masonry wallet (wire-support slip); potentiometers T2 and T3 surveyed the displacement between the base of the masonry wallet and the upper edge of the mortar coating layer (mainly masonry shortening).

All the instruments were connected to an electronic acquisition unit, interfaced with a computer. The acquisition frequency was $1 \mathrm{~Hz}$. The software allowed the real-time monitoring of the loading history, the displacement measured by the transducers and the load-displacement diagrams. Tests were performed at displacement control, on the basis of elongation detected by the potentiometer T1 (rate $0.5 \mathrm{~mm} / \mathrm{min}$ ).

\subsection{Test results and discussion}

The main characteristics and results of the tested samples are summarized in Table 4. Each sample is identified by an ID which distinguishes the GFRP grid dimensions ("A66" for $66 \times 66 \mathrm{~mm}^{2}$ and "A33" for $33 \times 33 \mathrm{~mm}^{2}$ ) and the mortar coating length ("1" for $120 \mathrm{~mm}$, "2" for $180 \mathrm{~mm}$ and " 3 " for $240 \mathrm{~mm}$ ); a final number, from 1 to 5 , differentiates specimens having the same features. The results are resumed in terms of peak load $P_{u}$, displacements $\delta_{T 1}, \delta_{T 2}$ and $\delta_{\mathrm{T} 3}$ monitored by transducers $\mathrm{T} 1, \mathrm{~T} 2$ and $\mathrm{T} 3$ at peak load and type of collapse.

Moreover, the tensile load $P$ at the varying of the mesh-mortar displacement $\left(\delta_{t-m}\right)$ is illustrated in Fig. 11. The value of $\delta_{t-m}$ was evaluated as the difference between the global mesh-support displacement $\left(\delta_{T 1}\right)$ and the mortar-support displacement (average of the displacements $\delta_{T 2}$ and $\delta_{T 3}$ ). It is evidenced that the displacement $\delta_{t-m}$ generally may be due to elongation of the mesh and to the relative mesh-mortar slippage. Actually, at the beginning of the test, there was the perfect adhesion between the mesh and the mortar, thus $\delta_{t-m}$ was initially determined by the strain of the vertical GFRP tensed wires, in the portion of wires ranging from the clamping of transducer T1 on the mesh to the lower border of the mortar coating (about $100 \mathrm{~mm}$ ). For comparison, the load 
Table 4

Main characteristics and results of the samples subjected to bond test.

\begin{tabular}{|c|c|c|c|c|c|c|c|}
\hline ID & Mortar layer $\left[\mathrm{mm}^{3}\right]$ & GFRP mesh $\left[\mathrm{mm}^{2}\right]$ & $P_{u}[\mathrm{~N}]$ & $\delta_{T 1}[\mathrm{~mm}]$ & $\delta_{T 2}[\mathrm{~mm}]$ & $\delta_{T 3}[\mathrm{~mm}]$ & Type of collapse \\
\hline A66-1-1 & $120 \times 132 \times 30$ & $66 \times 66-S$ & 5529 & 3.30 & 0.011 & 0.045 & Mesh slip and deboning of mortar from masonry \\
\hline A66-1-2 & $120 \times 132 \times 30$ & $66 \times 66-S$ & 6180 & 4.11 & 0.022 & 0.022 & Mesh slip within the mortar, with cracking of the mortar \\
\hline A66-1-3 & $120 \times 132 \times 30$ & $66 \times 66-S$ & - & - & - & - & Not performed, due to former damage of the sample \\
\hline A66-1-4 & $120 \times 132 \times 30$ & $66 \times 66-S$ & 8165 & 4.76 & 0.012 & - & Mesh slip and GFRP mesh rupture out of the bond area \\
\hline A66-1-5 & $120 \times 132 \times 30$ & $66 \times 66-S$ & 6143 & 1.96 & 0.011 & 0.024 & Mesh slip within the mortar, with cracking of the mortar \\
\hline A66-2-1 & $180 \times 132 \times 30$ & $66 \times 66-S$ & 9101 & 3.41 & 0.035 & 0.054 & Deboning of the mortar coating from the masonry \\
\hline A66-2-2 & $180 \times 132 \times 30$ & $66 \times 66-S$ & 9330 & 3.03 & 0.026 & 0.037 & GFRP mesh rupture out of the bond area \\
\hline A66-2-3 & $180 \times 132 \times 30$ & $66 \times 66-S$ & 9173 & 3.33 & - & 0.029 & Mesh slip within the mortar, with cracking of the mortar \\
\hline A66-2-4 & $180 \times 132 \times 30$ & $66 \times 66-S$ & 9596 & 3.03 & 0.015 & 0.023 & Deboning of the mortar coating from the masonry \\
\hline A66-2-5 & $180 \times 132 \times 30$ & $66 \times 66-S$ & 9283 & 6.90 & 0.014 & 0.049 & Deboning at mesh-to-mortar interface \\
\hline A66-3-1 & $240 \times 132 \times 30$ & $66 \times 66-S$ & 9861 & 4.12 & 0.047 & 0.096 & GFRP mesh rupture out of the bond area \\
\hline A66-3-2 & $240 \times 132 \times 30$ & $66 \times 66-S$ & 8844 & 3.33 & 0.034 & 0.045 & GFRP mesh rupture out of the bond area \\
\hline A66-3-3 & $240 \times 132 \times 30$ & $66 \times 66-S$ & 9177 & 4.10 & 0.017 & 0.028 & GFRP mesh rupture out of the bond area \\
\hline A66-3-4 & $240 \times 132 \times 30$ & $66 \times 66-S$ & 10081 & 4.12 & 0.014 & 0.032 & GFRP mesh rupture out of the bond area \\
\hline A66-3-5 & $240 \times 132 \times 30$ & $66 \times 66-S$ & 9605 & 3.11 & 0.015 & 0.026 & GFRP mesh rupture out of the bond area \\
\hline A33-3-1 & $240 \times 132 \times 30$ & $33 \times 33-S$ & 17061 & 3.09 & 0.068 & - & Deboning of the mesh-to-mortar interface \\
\hline A33-3-2 & $240 \times 132 \times 30$ & $33 \times 33-S$ & 17807 & 3.30 & 0.032 & - & Deboning of the mesh-to-mortar interface \\
\hline A33-3-3 & $240 \times 132 \times 30$ & $33 \times 33-S$ & 15735 & 2.73 & 0.060 & 0.049 & Deboning of the mesh-to-mortar interface \\
\hline A33-3-4 & $240 \times 132 \times 30$ & $33 \times 33-S$ & 15169 & 3.04 & 0.048 & 0.074 & Deboning of the mesh-to-mortar interface \\
\hline A33-3-5 & $240 \times 132 \times 30$ & $33 \times 33-S$ & 16263 & 2.70 & - & 0.029 & GFRP mesh rupture out of the bond area \\
\hline
\end{tabular}

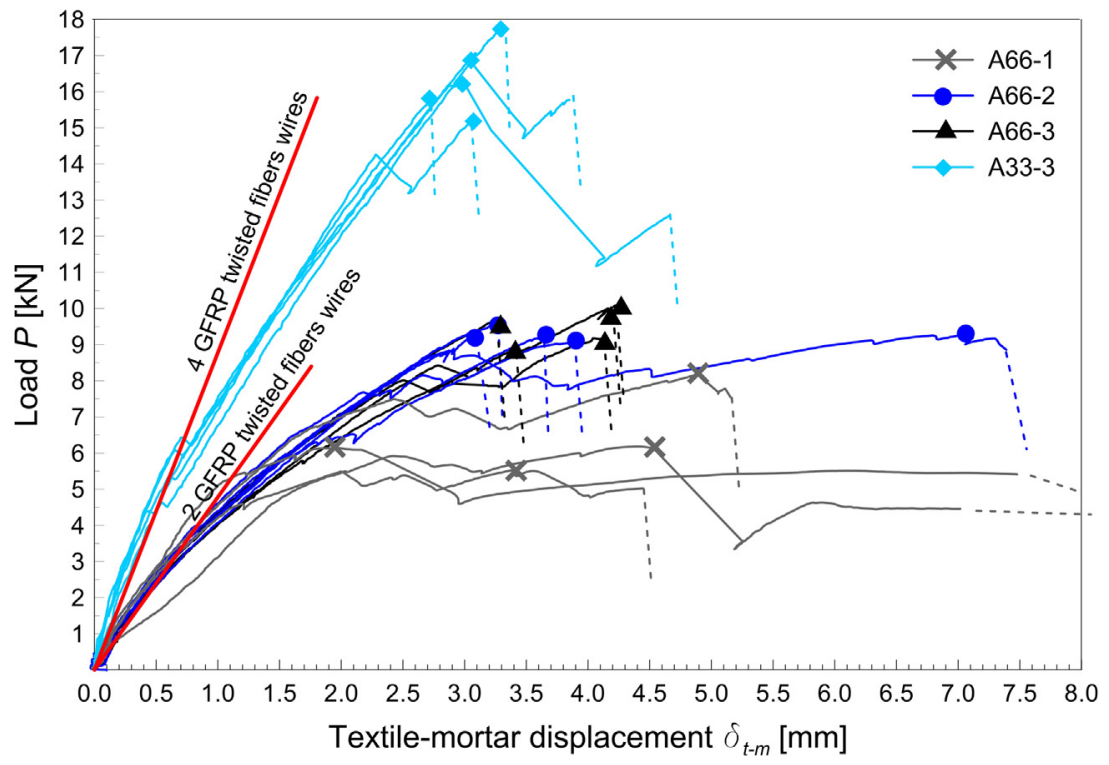

Fig. 11. Load $P$ against displacement $\delta_{t-m}$ of samples subjected to bond tests.

vs. elongation curves of 2 twisted fibers wires of the $66 \times 66 \mathrm{~mm}^{2}$ GFRP mesh and of 4 twisted fibers wires of a $33 \times 33 \mathrm{~mm}^{2}$ GFRP mesh were plotted in Fig. 11. The curves were evaluated considering the results of the characterization tests on GFRP wires reported in Table 1, referring to a $100 \mathrm{~mm}$ wire length.

The results of bond tests generally evidenced very low displacements between the masonry and the mortar coating $(<0.1 \mathrm{~mm}$, at peak load) in respect to those monitored between the mortar and the reinforcement ( $>3 \mathrm{~mm}$, at peak load).

In samples A66-1 an important mesh-mortar slippage was noted. The slip was, in general, so consistent that the deformation of the transversal wires induced a local cracking and detachment of the mortar covering the mesh (Fig. 12.a). The slippage affected the whole bond length: in fact, it was possible to clearly distinguish the slip of the vertical wires also at the upper edge of the mortar layer. Then, at the increasing of the slip, the load gradually decreased. Actually, the untwisting of the upper end of the longitudinal wires was noted at the end of the tests. The peak loads were quite similar for A66-1-1, A66-1-2 and A66-1-5 (about $6 \mathrm{kN}$, st. dev. 6\%); differently, an anomalous, higher value was obtained from A66-1-4 (8.2 kN), where the failure of the GFRP wires was attained.

Also in samples A66-2 the local, horizontal cracking of the mortar in correspondence of the lower transversal wire occurred, but then the load continued to increase until the abrupt debonding of the coating from the masonry (Fig. 12.b) or the failure of the GFRP wires (Fig. 12.c). The peak loads were quite similar and about $9.3 \mathrm{kN}$ (st. dev. 3\%)

In specimens A66-3, in general, no mortar cracking emerged and the GFRP wires rupture (Fig. 12.d) occurred for a mean value of $9.5 \mathrm{kN}$ (dev.st 5\%).

No visible wires slippage was noted at the end of the tests in correspondence of the upper edge of the mortar layer neither in A66-2 nor in A66-3 samples. It emerged, instead, a progressive deformation of the transverse wires in the free part of the mesh, as a consequence of the untwisting of the longitudinal wires. This deformation, in some cases also determined the failure of some of transversal wires during the test. 

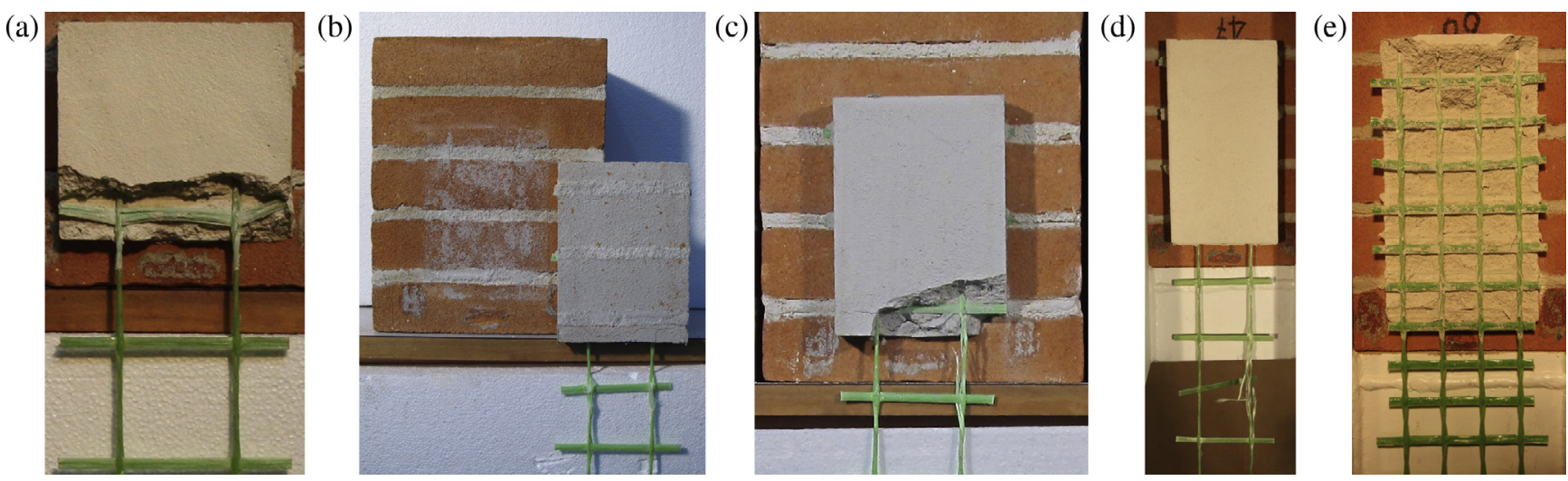

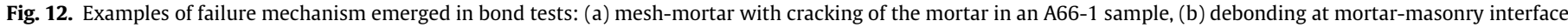
and (c) GFRP wire rupture in a A66-2 sample, (d) GFRP wire rupture in a A66-3 and (e) debonding of the mortar covering the mesh in a A33-3 sample.

In specimens A33-3, after the horizontal cracking of the mortar portion covering the mesh in correspondence of the lower transversal wire, the deboning of the mesh-to-mortar interface occurred abruptly in four samples (Fig. 12.e). Exception for specimen A33-3-5, where the GFRP wires collapsed. However, the values of maximum resistance were quite similar ( $16.4 \mathrm{kN}$, st.dev. $6 \%$ ).

Generally, the slope on the $F-\delta_{t-m}$ curves initially resulted in good agreement with the stiffness of the GFRP wires so, at the beginning of the test, the mesh can be assumed as perfectly bonded to the mortar. Then, a decrease in the curves slope emerged, which indicates the occurrence of the mesh-mortar slip. Actually, the beginning of this slip occurred at a load value of about $4 \mathrm{kN}$ for type A66 specimens and 5.5-6 kN for A33 ones. The value obtained from A66 samples resulted in agreement with that noted in preliminary tests (Section 3). Due to the higher amount of reinforcement, lower values of displacements $\delta_{t-m}$ were obtained from A33-3 specimens, in respect to A66-3 ones at the same load level.

Some other interesting aspects can be observed from the results:

- the resistance of A66 samples associated to the GFRP wire rupture (which is independent from the bond length) resulted, on average equal to $9.5 \mathrm{kN}$. This value is quite higher than that derived from tests on single wires $(2 \times 4.2 \mathrm{kN}=8.4 \mathrm{kN}$, see Table 1 ). This was probably due to the different boundary condition applied on the GFRP wires. In fact, during the characterization test, a gradual straighten of the twisted wires was noted until the rupture. Differently, during the tests on the GFRP reinforced mortar coating samples, the presence of the transversal wires partially opposed to these occurrence (as confirmed by their visible deformation and, sometimes, failure) and may have improved the tensile characteristics of the composite mesh;

- the mesh-mortar slippage resistance, referred to a $120 \mathrm{~mm}$ bond length, resulted on average equal to $6.2 \mathrm{kN}$ (A66-1-2 and A66-1-4 samples). This value is quite lower than that obtained from pull-out tests on plate samples $(2 \times 4.1 \mathrm{kN}=8.2 \mathrm{kN}$, see Table 2) as the effectiveness of the mesh nodes against the slippage was partially limited by the occurrence of the horizontal cracking in correspondence of the lower transversal wire and by the subsequent untwisting of the upper end of the longitudinal wires, once the chemical adhesion of the longitudinal wires to the mortar completely failed. Reasonably, at the increasing of the bond length, the mesh-mortar slippage should be more than linearly proportional to this parameter, as 4 or 8 mesh nodes in A66-2 and A66-3 specimens, respectively, offer effective resistance to sliding;
- the equivalent bond strength to the masonry substrate (deduced from specimens A66-2-1 and A66-2-4, by dividing the peak load for the whole bond area) resulted on average $\tau_{b}=0.39 \mathrm{MPa}$. If a simplified linear trend of the bond resistance is assumed, a value of $6.2 \mathrm{kN}$ and $12.4 \mathrm{kN}$ for specimens having a $120 \mathrm{~mm}$ and a $240 \mathrm{~mm}$ length, respectively, emerged. Actually, the value for $120 \mathrm{~mm}$ bond length samples resulted quite close to that associated to the failure for mesh-mortar slippage. Diversely, the value for $240 \mathrm{~mm}$ bond length specimens resulted higher than that associated to the wires failure in A66-3 samples and lower than that associated both to the wires failure and to the debonding of the mesh-mortar interface in A33-3 samples. Actually, the debonding of the mortar coating from the masonry did not occur in the latter type of samples and load values higher than $12.4 \mathrm{kN}$ were attained. Deeper investigations are needed on the mortar-masonry bond resistance, because many parameters, such as the presence of mortar joints and the actual distribution of the shear load, may affect this aspect [25].

- the debonding at mesh-mortar interface in A33-3 specimens may have been induced by the weakening of the shear plane due to the high reinforcement ratio.

\section{Tensile tests on reinforced mortar layers}

In this section are described the characteristics and the results of some tensile tests carried out on mortar layers with GFRP meshes embedded, so to evaluate the performances of the reinforcement when subjected in tension and the effect of the intact mortar between cracks (tension stiffening).

\subsection{Specimens characteristics}

The tensile behavior of the GFRP reinforced mortar coating was assessed through experimental tests. The specimens consisted in a $132 \times 900 \mathrm{~mm}^{2}$ layer of mortar plaster, $30 \mathrm{~mm}$ thick, with a $66 \times 66 \mathrm{~mm}^{2}$ GFRP mesh embedded in the center of the mortar thickness, with the two twisted wires disposed in the longitudinal direction and arranged symmetric to the specimen width (Fig. 13. a). Seven specimens were prepared (TA66-1 to 7); the packaging and the curing of the reinforced mortar layers followed the steps already described in Section 3 for pull-out samples. Once the designed mortar curing was completed, the clamping heads of the samples were created. In particular, on the faces of each specimen, at both ends, two overlapped strips of Carbon FiberReinforced Polymers were applied by the impregnation of the fab- 
(a)

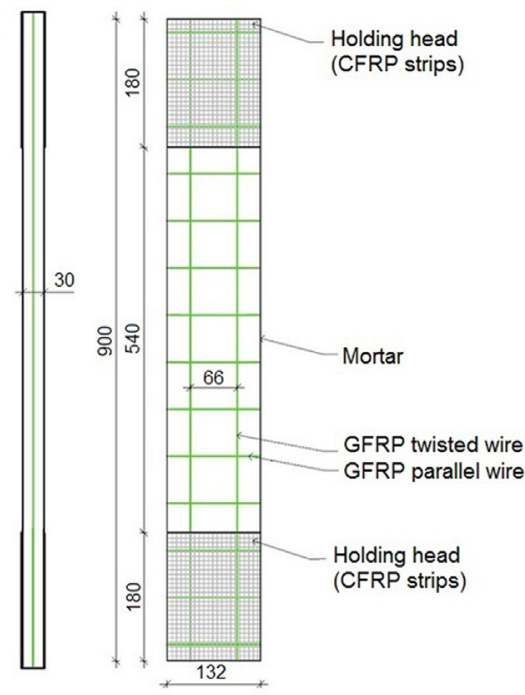

(b)

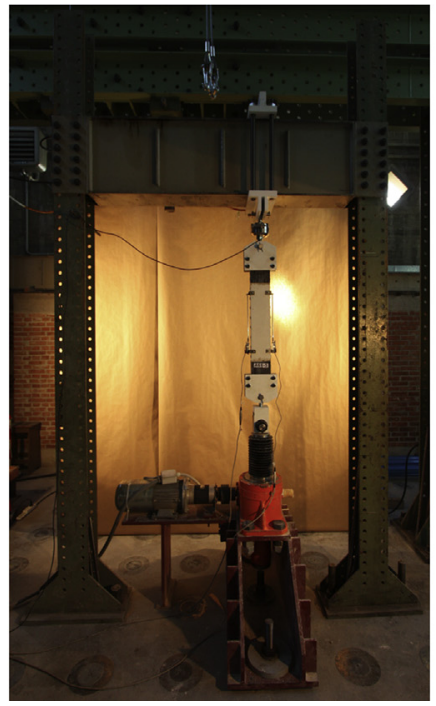

(c)

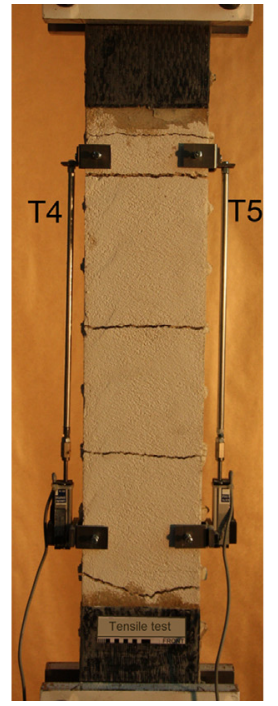

(d)

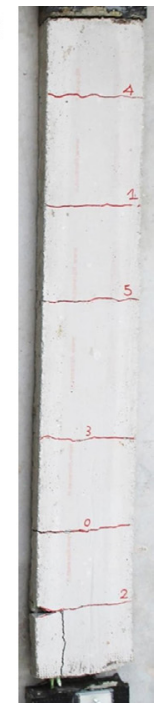

Fig. 13. Tensile test: (a) GFRP reinforced mortar layer samples TA66, (b) test setup and view of samples (c) TA66 and (d) TB66 at the end of the tests.

ric with bicomponent epoxy resin. The reinforcement was aimed to avoid local load concentrations and damages during the test in correspondence of the gripping areas. The width of this reinforcement was equal to that of the sample while the length was $180 \mathrm{~mm}$, that is about the anchorage length needed to prevent mesh-to-mortar slippage (as emerged in bond tests - Section 4).

\subsection{Test setup and loading procedure}

The test apparatus for this type of tensile tests ("TA") was for the most the same of that employed for bond tests (Section 4) replacing the metallic device to support the specimen with two steel plates constituting the upper holding of the sample, with the same characteristics of the lower one (Fig. 13.b). The grip was realized on a clamping length of about $90 \mathrm{~mm}$. The knuckle joints ensured the application of axial load only without any parasitic bending. Two potentiometer transducers were installed along the specimens by means of C-shape steel clamps, applied to the mortar through tightening screws (Fig. 13.c), with the aim to monitor the elongation during the application of the load; the base length was $400 \mathrm{~mm}$. The tests were performed at displacement control after about 80 days of mortar curing; the loading rate was about $0.04 \mathrm{~mm} / \mathrm{min}$ in the un-cracked phase, $1.0 \mathrm{~mm} / \mathrm{min}$ in the cracked one.

\subsection{Test results and discussion}

The results of the tensile tests are summarized in Table 5 in terms of first cracking load $T_{c r}$, peak load $T_{\max }$ and displacements $\delta_{T 4}$ and $\delta_{T 5}$ measured by the transducers T4 and T5 in correspondence of $T_{c r}$ and $T_{\max }$. The number of transversal cracks noted at the end of the tests and detected by the transducers was also indicated.

The tensile stresses in correspondence of the first cracking $\left(\sigma_{c r}\right)$ and of the maximum resistance $\left(\sigma_{\max }\right)$ were also evaluated in respect to the cross section of dry fibers $\left(3.8 \mathrm{~mm}^{2} \times 2=7.6 \mathrm{~mm}^{2}\right)$; moreover the mean tensile strains $\varepsilon_{c r}$ and $\varepsilon_{\max }$ were calculated by dividing the average displacements for the measurement base length $l_{d}$. The curves representing the tensile stress $\sigma$ at the varying of the mean strain $\varepsilon$ were plotted in Fig. 14 .

A first elastic branch was generally detected by the displacement transducers, as the mortar was uncracked. Then, a first, horizontal crack formed, resulting in a sudden decrease of the load. The tensile force increased then again, until the formation of another crack. Other horizontal cracks gradually appeared in the mortar, located, for the most, in correspondence of transversal mesh wires. As the number of cracks stabilized, the load increased until the rupture of the longitudinal wires (Fig. 13.c), in correspondence of a crack, determining the sample failure at about $11.0 \mathrm{kN}$

Table 5

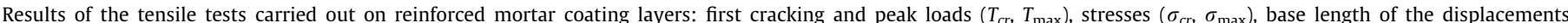

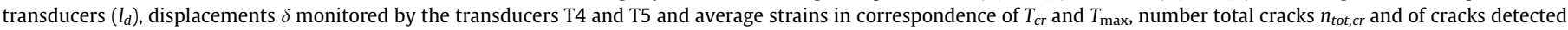
by the transducers $n_{\text {tot,mis }}$ and average crack distance $\Delta_{c r, \mathrm{~m}}$.

\begin{tabular}{|c|c|c|c|c|c|c|c|c|c|c|c|c|c|c|}
\hline ID & $\begin{array}{l}T_{c r} \\
{[\mathrm{~N}]}\end{array}$ & $\begin{array}{l}T_{\max } \\
{[\mathrm{N}]}\end{array}$ & $\begin{array}{l}\sigma_{c r} \\
{[\mathrm{MPa}]}\end{array}$ & $\begin{array}{l}\sigma_{\max } \\
{[\mathrm{MPa}]}\end{array}$ & $\begin{array}{l}l_{d} \\
{[\mathrm{~mm}]}\end{array}$ & $\begin{array}{l}\delta_{T 4}\left(T_{c r}\right) \\
{[\mathrm{mm}]}\end{array}$ & $\begin{array}{l}\delta_{T 5}\left(T_{c r}\right) \\
{[\mathrm{mm}]}\end{array}$ & $\begin{array}{l}\varepsilon_{c r} \\
{[0 \% 00]}\end{array}$ & $\begin{array}{l}\delta_{\mathrm{T} 4}\left(T_{\max }\right) \\
{[\mathrm{mm}]}\end{array}$ & $\begin{array}{l}\delta_{T 5}\left(T_{\max }\right) \\
{[\mathrm{mm}]}\end{array}$ & $\begin{array}{l}\varepsilon_{\max } \\
{[0 \% 00]}\end{array}$ & $\begin{array}{l}n_{c r, t o t} \\
{[-]}\end{array}$ & $\begin{array}{l}n_{c r, m i s} \\
{[-]}\end{array}$ & $\begin{array}{l}\Delta_{c r, m} \\
{[\mathrm{~mm}]}\end{array}$ \\
\hline TA66-1 ${ }^{*}$ & - & 10094 & - & 1328 & 400 & - & - & - & 5.77 & 5.20 & 13.71 & $3(+1)$ & $1(+1)$ & 149 \\
\hline TA66-2 & 4923 & 9802 & 648 & 1290 & 400 & 0.005 & 0.058 & 0.08 & 6.97 & 5.56 & 15.66 & 4 & 2 & 154 \\
\hline TA66-3 & 4974 & 10072 & 654 & 1325 & 400 & 0.046 & 0.082 & 0.16 & 8.71 & 8.27 & 21.23 & 5 & 3 & 116 \\
\hline TA66-4 & 5172 & 11301 & 681 & 1487 & 400 & 0.013 & 0.072 & 0.11 & 8.31 & 8.96 & 21.59 & 5 & 3 & 116 \\
\hline TA66-5 & 4403 & 9573 & 579 & 1260 & 400 & 0.001 & 0.063 & 0.08 & 4.27 & 4.59 & 11.08 & 3 & 1 & 231 \\
\hline TA66-6 & 4852 & 13753 & 638 & 1810 & 400 & 0.079 & 0.029 & 0.14 & 10.78 & 10.24 & 26.28 & 5 & 3 & 132 \\
\hline TA66-7 & 4016 & 12498 & 528 & 1644 & 400 & 0.011 & 0.038 & 0.06 & 8.39 & 9.21 & 22.00 & 5 & 3 & 108 \\
\hline TB66-1 & 5828 & 12137 & 767 & 1597 & 830 & 0.038 & - & 0.05 & 8.90 & - & 12.26 & 7 & 7 & 110 \\
\hline TB66-2 & 5230 & 11055 & 688 & 1455 & 830 & 0.044 & - & 0.06 & 6.81 & - & 9.38 & 6 & 6 & 132 \\
\hline TB66-3 & 5088 & 11816 & 669 & 1555 & 830 & 0.060 & - & 0.08 & 9.04 & - & 12.45 & 7 & 7 & 110 \\
\hline TB66-4 & 3112 & 12367 & 409 & 1627 & 830 & 0.035 & - & 0.05 & 9.07 & - & 12.49 & 6 & 6 & 132 \\
\hline
\end{tabular}

Presence of a crack in the specimen before starting the test. 


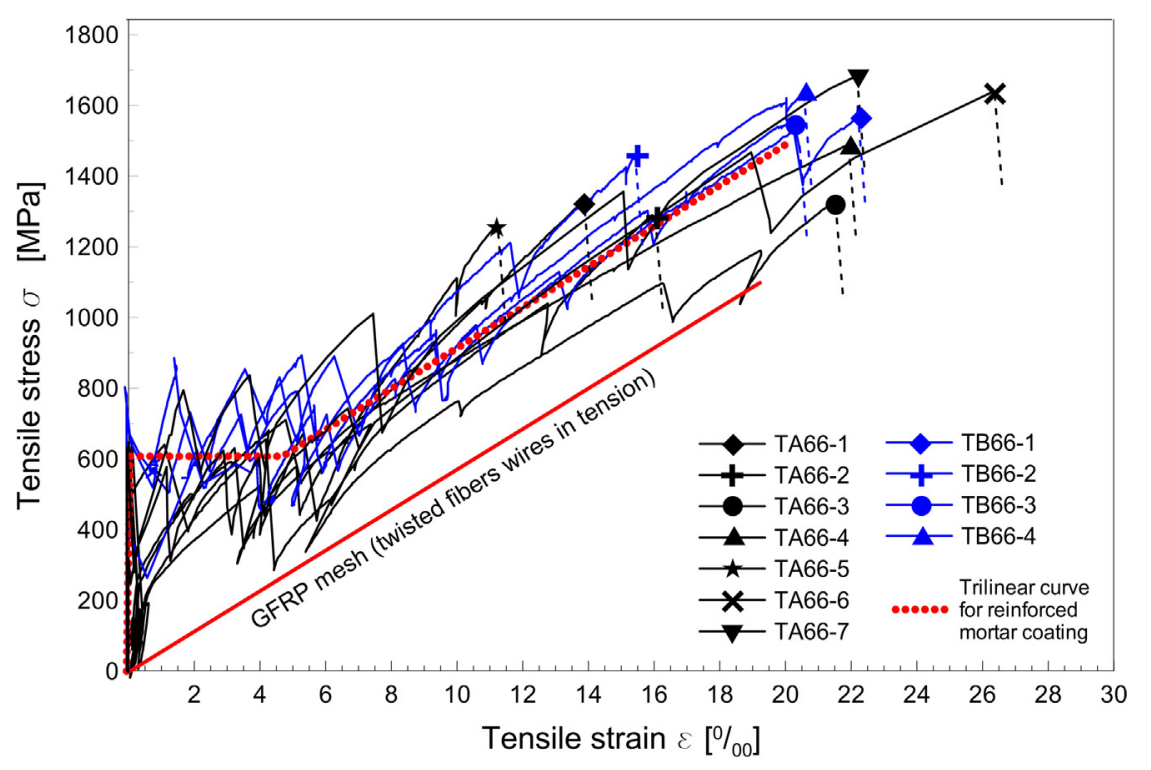

Fig. 14. Tensile tests "TA66" and "TB66": stress $\sigma$ against strain $\varepsilon$ curves.

(st. dev. 14\%). It is observed that in samples TA66-3, TA66-4, TA666 and TA66-7, 5 cracks formed and the couple of transducers were able to survey the opening of 3 cracks. Diversely, a lower number of cracks ( 2 or 1 ) were included in the measure length in TA66-1, TA66-2 and TA66-5. Moreover, in TA66-1, the presence of an existing horizontal crack was noted in the specimen before testing, resulting in a lower initial stiffness of the $\sigma-\varepsilon$ curve.

To account for a possible influence of the gripping mechanism on the GFRM samples behavior [26], a second set of tensile tests were performed on reinforced mortar layers $860 \times 132 \times 30 \mathrm{~mm}^{3}$, with tensile load applied directly to the GFRP mesh, which exceeded from the ends of the mortar coating. To apply the load, reinforced concrete tabs $\left(f_{c \text {,concrete }}=25 \mathrm{MPa}\right)$, wrapped with CFRP strips impregnated with epoxy resin, were created for embedding the GFRP mesh ends and clamping the specimens to the holding plates of the testing machine. The same preparation, curing and loading conditions considered in "TA66" samples were assumed. A single transducer displacement (T4) was applied on the samples, at the center of the mortar layer face. The base length was approximately $830 \mathrm{~mm}$.

Four samples were tested for this typology (identified as type "TB66" - Fig. 13.d); the results are summarized in Table 5 and plotted in the stress-strain graph of Fig. 14. The same collapse mechanism evidenced in type "TA66" specimens was noted and the $\sigma-\varepsilon$ curves are, in general, comparable. This indicates that even a possible slippage in the clamping heads of type "TA66" did not influenced the results and that a base length of $400 \mathrm{~mm}$ can be sufficient to provide a quite accurate evaluation of the mean performances of the GFRP reinforced mortar layer.

The higher scatters noted in the diagrams representing the behavior of specimens TA66-1 and TA66-5 were induced by the formation of only one crack along the base length. Thus, in these cases, the curve cannot be considered as representative on the average behavior of the reinforced material, as at least two cracks has to be detected by the transducers.

Generally, the performances of the specimens can be schematized by a trilinear behavior characterised by a pre-cracking, elastic branch, with stiffness dependent on the mortar Young modulus, a multiple cracking formation branch (assumed horizontal) and a post-cracking branch, until the tensile rupture of the wires. This last branch can be assumed parallel to the curve representing the tensile behavior of the GFRP wires alone. The horizontal gap between the third branch of the trilinear curve and that representing the GFRP wires represents the tension stiffening effect of the mortar between the cracks.

For comparison, the stress-strain curve of a GFRP twisted wire was plotted in Fig. 14. It is observed that, in general, the final slope of the $\sigma-\varepsilon$ curves well accords with the wire stiffness. The average, simplified trilinear curve representing the global behavior of the GFRP reinforced mortar layer is plotted in Fig. 14. It is observed that the curve was derived considering only the specimens in which the transducers were able to detect at least two cracks.

Finally, it is evidenced that the maximum stress resulted higher than that derived from the wire resistance obtained in the characterization tests (see Section 2). As already evidenced in 4.3, this was probably due to the different boundary condition applied on the GFRP wires and, in particular, to the presence of the transversal wires embedded in the mortar layer.

To evidence the importance of design tensile tests on reinforced mortar layers with an anchorage length adequate to the mesh and matrix characteristics, an example of a non-acceptable specimen failure is reported. It refers to samples $30 \times 198 \times 900 \mathrm{~mm}^{3}$ of mortar, with a $99 \times 99 \mathrm{~mm}^{2}$ GFRP mesh embedded ("TA99") Fig. 15.a. A $180 \mathrm{~mm}$ anchorage length was considered, analogously to "TA66" specimens. The transducer T5 had a base length of $400 \mathrm{~mm}$, diversely the transducer T4 was installed on a base length $580 \mathrm{~mm}$, so to be able to measure the opening of all the cracks. An illustration of a "TA99" specimen at the end of the test is reported in Fig. 15.b as an example. Some horizontal cracks formed; at the occurrence of cracking in the vicinity of the anchorage length, the gradual extraction of the longitudinal GFRP wires from the holding head emerged and induced the sample failure. The rupture of GFRP wires was never reached.

The amount of the mesh slippage from the lower clamping head can be estimated as the difference between the displacements monitored by the transducers at the varying of the tensile load (Fig. 15.c); in fact, the lower crack formed outside the transducer T5 base length.

Due to this slippage, which resulted of about $7.3 \mathrm{~mm}$ in correspondence of the peak load, there was not possible to detect a post-cracking branch parallel to the curve representing the tensile behavior of the GFRP wires alone. This type of collapse has to be considered not acceptable: in fact, is related to the test setup. In particular, the slippage emerged in these tests was due to the mesh 
(a)

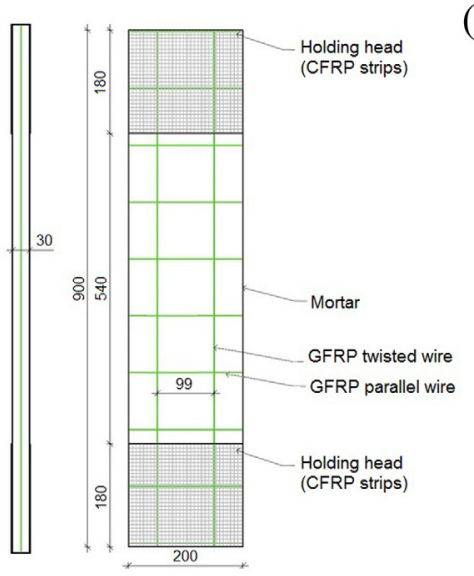

(b)

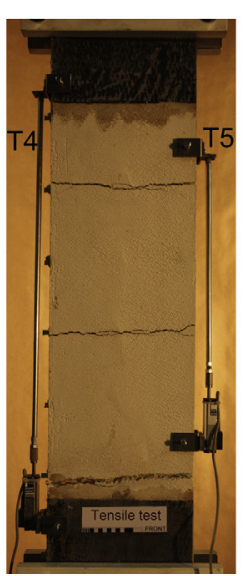

(c)

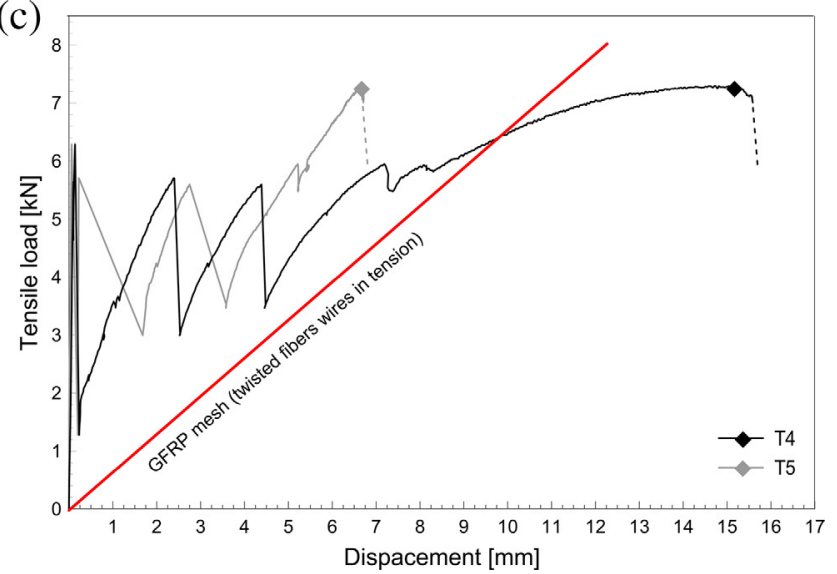

Fig. 15. Tensile tests TA99: (a) samples characteristics, (b) view at the end of the tests and (c) example of $\sigma-\varepsilon$ curve.

arrangement: a single transversal wire was present in the anchorage length. Actually, pull-out (ection 3.1) and bond tests (Section 4) evidenced that transversal wires offer an important contribution against slippage.

\section{Conclusions}

The results of some experimental tests concerning the characterization of a reinforcement technique for existing masonry buildings based on a $66 \times 66 \mathrm{~mm}^{2}$ GFRP mesh embedded in a $30 \mathrm{~mm}$ thick mortar coating are presented and discussed in the paper.

At first, some preliminary pull-out and lap-splice tests were performed so to investigate, through small samples, on the interaction between the composite reinforcement and the inorganic matrix and on the influence of the boundary conditions on the tests results. In particular, the tests permitted to evidence that the slip of the wire embedded in the mortar occurred for loads considerably lower than the bond resistance obtained, which was quite close to the wire tensile strength. So the bond resistance is guaranteed by the mechanical contribution due to transversal wires acting as dowels.

The tests carried out on diverse specimens, plate and cylindrical, did not show appreciable differences in terms of resistance even though the type of collapse was different: occurrence of a splitting crack in the plate elements in the wire direction that emphasize again the important role of transversal wires of the mesh for bond resistance.

Preliminary tests indicated that a bond length of $120 \mathrm{~mm}$ should be sufficient to guarantee the collapse of the specimen for twisted fibers wire rupture.

Bond and tensile tests were then performed with two twisted fibers wires oriented in the load direction. A particular attention was paid in the design of the test setup, especially regarding the correct alignment of the loading forces, so to avoid parasitic flexure which may cause premature failures, and the adequate stiffness of the contrast device, so to permit the execution of the tests at displacement control.

For bond tests on masonry substrate, three different bond length were considered: 120,180 and $240 \mathrm{~mm}$. In general, in the former case the debonding of the mesh from the mortar matrix occurred. In fact, the transversal cracking of the mortar occurred, compromising the contribution of the mesh nodes against the slippage. In the latter case, the failure for longitudinal wires rupture was obtained. In the intermediate case, different failure mechanism manifested (wires rupture, debonding of the mortar, debonding of the composite); however, similar loads and close to the wires resistance were attained. Thus, a bond length of at least $180 \mathrm{~mm}$ has to be guaranteed in order to exploit the maximum resistance of the considered reinforcement.

On the contrary, shear tests performed on $240 \mathrm{~mm}$ bond length specimens considering a $33 \times 33 \mathrm{~mm}^{2}$ GFRP mesh evidenced the premature failure for mortar deboning at mesh-to-mortar interface. However, the reached load resulted very close to the wires resistance, thus the minimum bond length could be assumed approximately equal to $240 \mathrm{~mm}$.

Tensile tests permitted to evaluate the tensile performance of reinforced mortar layers. In particular, a tension stiffening effect of the intact mortar between the cracks was evidenced from the experimental results. Moreover, it is observed that the average distance between cracks is approximately $125 \mathrm{~mm}$ and that different test setups, based on the mortar or on the GFRP mesh loading, provide similar results. Finally, it is important to ensure an appropriate anchorage length so to achieve a type of collapse that is independent from the test setup. The deduced stress-strain curve is representative of the average behavior of the reinforced material if at least two cracks occur inside the measurement base length.

From both tensile and bond tests emerged a tensile resistance of the GFRP twisted fibers wires higher than that evaluated trough characterization tests on single wires, due to the presence of mesh transversal wires which oppose to the progressive un-twisting of tensed wires at the increasing of the load.

Further shear and tensile tests are needed to evaluate the bond and tensile performances of the reinforcement technique when the parallel fibers wires are oriented in the loading direction. Also $99 \times 99 \mathrm{~mm}^{2}$ GFRP mesh in bond and tension and $33 \times 33 \mathrm{~mm}^{2}$ GFRP mesh in tension should be investigated. Moreover, different masonry supports and mortar types should be considered. However, the obtained results provide some important advices for the definition of correct testing procedures for characterization tests of FRM strengthening systems and permitted to evaluate the mechanical properties of the considered reinforcement technique useful for numerical simulations and analytical design purposes.

\section{Acknowledgments}

This paper is based on part of the results of a research project promoted by RILEM Technical Committee 250-CSM "Composites for Sustainable Strengthening of Masonry". The financial support of the composite engineering factory Fibre Net S.r.l., Udine, Italy, is gratefully acknowledged. Moreover, the useful help provided by Dr. Franco Trevisan, technician of the Laboratory of Testing Materials, University of Trieste, needs to be mentioned. 


\section{References}

[1] Schwegler G, Kelterborn P. Earthquake resistance of masonry structures strengthened with fiber composites. In: Proceedings of 11th World Conference on Earthquake Engineering, Acapulco, Mexico; 1996.

[2] Ehsani MR, Saadatmanesh $\mathrm{H}$. Method of strengthening masonry and concrete walls with composite strip and high strength random fibers. U.S. Patent No. 5,640,825, United States Patents and Trademark Office, Washington, D.C.; 1997.

[3] Triantafillou T. Strengthening of masonry structures using epoxy-bonded FRP laminates. J Compos Constr 1998;2(2):96-104.

[4] Chrysostomou CZ, Demetriou T, Pittas M. Conservation of historical Mediterranean sites by innovative seismic-protection techniques. In: Proc. 3rd world conference on structural control, vol. 2. Como, Italy; 2002. p. 94754.

[5] Galati N, Tumialan G, Nanni A. Strengthening with FRP bars of URM walls subject to out-of-plane loads. Constr Build Mater 2006;20(1-2):101-10.

[6] Korany Y, Drysdale R. Rehabilitation of masonry walls using unobtrusive FRP techniques for enhanced out-of-plane seismic resistance. J Compos Constr 2006;10(3):213-22.

[7] Turco V, Secondin S, Morbin A, Valluzzi MR, Modena C. Flexural and shear strengthening of un-reinforced masonry with FRP bars. Compos Sci Technol 2006;6(2):289-96.

[8] Corradi M, Borri A, Vignoli A. Experimental evaluation of the in-plane shear behaviour of masonry walls retrofitted using conventional and innovative methods. J Br Mason Soc 2008;21(1):29-42.

[9] Papanicolaou CG, Triantafillou TC, Papathanasiou M, Karlos K. Textile reinforced mortar (TRM) versus FRP as strengthening material of URM walls: out-of-plane cyclic loading. Mater Struct 2008;41(1):143-57.

[10] Galal K, Sasanian N. Out-of-plane flexural performance of GFRP-reinforced masonry walls. J Compos Constr 2010;14(2):162-74.

[11] Kadam SB, Singh Y, Li B. Strengthening of unreinforced masonry using welded wire mesh and micro-concrete - behaviour under in-plane action. Constr Build Mater 2014;54:247-57.

[12] Ismail N, Ingham JM. In-plane and out-of-plane testing of unreinforced masonry walls strengthened using polymer textile reinforced mortar. Eng Struct 2016;118:167-77.

[13] Leone M, Aiello MA, Balsamo A, Carrozzi FG, Ceroni F, Corradi M, et al. Glass Fabric Reinforced Cementitious Matrix: tensile properties and bond performance on masonry substrate. Technical Report of the Rilem Committee 250-CSM "Composites for Sustainable Strengthening of Masonry", 2016

[14] Corradi M, Borri A, Castori G, Osofero AI. Durability of GFRP grids for masonry structures. Int J Forensic Eng 2016;3(1/2).

[15] Gattesco N, Boem I. Experimental and analytical study to evaluate the effectiveness of an in-plane reinforcement for masonry walls using GFRP meshes. Constr Build Mater 2015;88:94-104.

[16] Gattesco N, Boem I. Out-of-plane behaviour of masonry walls strengthened with a GFRP reinforced mortar coating. In: Proceedings of the 9th International Masonry Conference, 7-9 July, Guimarães (PT); 2014.

[17] Gattesco N, Boem I. Strengthening of masonry vaults through a thin extradoxa layer of fiber reinforced lime mortar. In: Proceedings of the 10th International Conference on Structural Analysis of Historical Constructions - SAHC, 13-15 September, Leuven (BE); 2016.

[18] Castori G, Borri A, Corradi M. Behavior of thin masonry arches repaired using composite materials. Compos B Eng 2015;87:311-21.

[19] CNR DT 203/2006. Istruzioni per la progettazione, l'esecuzione ed il controllo di strutture di calcestruzzo armato con barre di materiale composito fibrorinforzato.

[20] Gattesco N, Boem I. Influence of mortar coating type on the shear resistance of a GFRP based strengthening technique for brick masonry walls. In: Proceedings of the 16th International Brick and Block Masonry Conference IB2MAC, 26-30 June, Padua (I); 2016.

[21] EN 196-1:2005. Methods of testing cement - Part 1: Determination of strength.

[22] EN 12390-6:2009. Testing hardened concrete - Part 6: Tensile splitting strength of test specimens.

[23] EN 12390-13:2013. Testing hardened concrete - Part 13: Determination of secant modulus of elasticity in compression CEN, Brussels.

[24] EN 772-1:2011+A1:2015. Methods of test for masonry units - Part 1: Determination of compressive strength.

[25] Napoli A, De Felice G, De Santis S, Realfonzo R. Bond behaviour of Stee Reinforced Polymer strengthening systems. Compos Struct 2016;152:499-515.

[26] De Santis S, De Felice G. Tensile behavior of mortar-based composites for externally bonded reinforcement systems. Compos B 2015;68:401-13. 